\title{
Ethni-cities: Residential Patterns in the Northern European and Mediterranean Metropolises - Implications for Policy Design
}

Jorge Malheiros*

Universidade de Lisboa, Lisbon, Portugal

\section{ABSTRACT}

This paper examines how the role of Southern Europe in international migration systems has changed, from that of a source to a destination region, and how this is reflected in the emergence of new patterns of ethnic segregation. Areas where immigrants cluster are also areas with relatively high levels of social and housing deprivation. As a result, ethnic residential segregation is in part an expression of social exclusion. In the first part of the paper, a statistical analysis of secondary data provides an overview of the levels and distribution of ethnic segregation in Greece, Italy, Portugal and Spain. The second part of the paper examines the implications of the spatial organisation of immigrant communities for the development of territorial policies, and explores this through a comparative study of Lisbon and Rotterdam. The analysis also deals with territorialised policies developed in areas where immigrants cluster. Copyright (C) 2002 John Wiley \& Sons, Ltd.

Received 3 March 2001; revised 15 June 2001; accepted 1 September 2001

Keywords: ethnic minorities; residential segregation; suburbanisation; Mediterranean metropolises; Lisbon; Rotterdam

\footnotetext{
* Correspondence to: J. Malheiros, Centro de Estudos Geográficos, Universidade de Lisboa, Alameda da Universidade 1600-214 Lisboa, Portugal.

Email: jmalheiros@hotmail.com
}

\section{INTRODUCTION}

7 he last quarter century of the old millennium changed the face of the Southern European metropolises. After the significant internal migration processes of previous decades, which enlarged the urban population and converted the cities into metropolitan areas, indigenous newcomers were replaced by external migrants.

As in earlier decades, large North Mediterranean cities are major destinations of contemporary immigrants, but the old geographically circumscribed centre-periphery relations that involved the industrialising urban centres and the less developed regions of these countries have been replaced by larger-scale interaction processes. Nowadays, the relatively dense and diversified formal and informal urban labour markets of Southern Europe have influence areas well beyond the national boundary limits, involving distant regions that, through the current process of time-space squeezing, became the regional peripheries of the twenty-first century.

Spanish-type quota systems, Portuguesetype special agreements and the panoply of restrictive regulations that try to limit the access of foreigners to EU space are examples of regulatory processes aiming to control and direct immigrant flows. But beyond these formal issues, non-formal links resulting from historical and cultural processes (a colonial past, language affinities, and so on) and specific social relations (the role of migratory cultures or widely discussed family and kinship networks) have a strong influence on the establishment of particular geographical inter- 
actions, connecting urban (or even intraurban) destinations in Southern European cities and origin regions situated in less developed countries. This points to a new territorial logic, where spatial polycentric networks involving distant localities prevail over continuous space.

The paper is organised into two parts and deals with this new situation of Southern European metropolises as receiving local societies experiencing related processes of change. The first part discusses the formation and development of spatial residential clusters of immigrants in deprived urban areas, in some cases the inner city, but frequently suburbia. The emergence of residential segregation based on ethnicity is a new feature of the contemporary development cycle of Southern European cities. The problem is not segregation in itself, but the coexistence of several negative elements in the areas where immigrants cluster: deprived housing and poor public space, over-representation of social problems like unemployment, drug traffic and lack of childhood assistance as well as reduced economic dynamics. The residential segregation of ethnic minorities is, in some ways, an expression of social exclusion.

In this part we present a hypothesis aiming to explain the originality of the spatial organisation of the immigrants and ethnic minorities in the cities of the four Southern European countries of the EU (Portugal, Spain, Italy and eventually Greece). In this hypothesis, it is assumed that a combined set of factors affecting both the immigration features and the socio-urban development of the metropolises of Southern Europe produces four distinctive processes:

- poorer housing conditions;

- high levels of informality in access to the real estate market;

- lower levels of spatial segregation associated with more complex patterns of residential distribution;

- a higher degree of suburbanisation of nonEuropean groups.

The second part of the paper deals with territorialised policies developed in areas where immigrants cluster. Using the examples of Rotterdam and Lisbon as a reference, we try to show the implications of the Northern European and Southern European patterns of spatial organisation of immigrants for the design of specific urban neighbourhood policies. Despite the common trends identified in the urban rehabilitation interventions developed in several EU metropolises after the late 1980s/early 1990s, stressed by EU initiatives such as URBAN, the policy principles of the Northern European cities, where these processes started earlier, cannot be assumed as references to the Southern European metropolises, without deep critical reflection. This paper tries to contribute to this debate.

\section{THE SEGREGATION ISSUE}

Since the 1920s Chicago School, several experts from different disciplinary fields have researched the specific social dynamics of urban environments and their associated spatial organisation features. Urban spatial segregation, corresponding to the analysis of spatial separation of different social and ethnic groups in the city ${ }^{2}$ is a major issue within the abovementioned topic.

Since its development in the early nineteenth century in England, the capitalist city has been socially and ethnically segregated. In his analysis of 1840s Manchester, Engels (1844/1975) stated:

'The city itself is built in such a way that we may live in it for years, come in and out daily and still never find a workers' neighbourhood or even a worker (...). This is mainly due to the fact that workers' quarters - either by unconscious agreement, or by an intentional action - are rigorously separated from the city parts occupied by bourgeoisie (...) or dissimulated under the veil of charity.'3

Although this image corresponds to social segregation, Engels' (1844/1975) analysis already incorporated an ethnic and migratory one, because Irish families were dominant (or at least over-represented) in several of the poorest quarters of Manchester.

The Fordist accumulation regime that emerged in the early twentieth century developed after the Second World War in North America and Western Europe, and is associated with modernist planning strategies 
which incorporate the notion of functional separation and have contributed to the deepening of social segregation. The development of the Fordist regime in the post Second World War period was clearly connected with Keynesianism, assuming a fundamental state role in controlling wages and ensuring social order, redistributing some of the benefits of the 'success capitalism' in the 1950s and 1960s, and ensuring relevant public investment in sectors like transport, communication and housing. As mentioned by Harvey (1990: 132), state-sponsored intervention, including the development of planned suburbia, helped to support the expansion of effective demand, a critical factor in the successful development of post-war Western capitalism.

The development of functional cities through zoning, enabling the spatial segregation of different urban functions, was a major factor in the process that has led to a related increase in the efficiency and effectiveness of production systems. As shown by Cullingworth (1993), zoning always produces some exclusion, not only functional but also social. The development of planned residential suburban areas of single family homes, especially in the US but to a lesser extent in European countries like the UK, Belgium and even the Netherlands, was a strategy of increasing family consumption and also of building a quality of life that matched the socio-cultural models of the prosperous 'middle-classes' that have become the symbol of this cycle of 'happy capitalism'. Through planning legislation that established norms like the minimum lot sizes for each residential area, and less formal practices limiting the access of certain population groups to certain neighbourhoods, modernist planning has certainly contributed to the exclusion of unwanted people in certain areas, and in consequence to the reinforcement of the mechanisms of segregation (Ball et al., 1985; Cullingworth, 1993).

Especially in northwestern Europe, this process was associated with an increase in the provision of social housing, although this sector was never completely placed in the public sphere, even in states with a social democratic orientation such as Sweden or the Netherlands (Esping-Andersen, 1990). Because the access to urban land was regulated by the market in several countries, and the offer of public housing respected the zoning principles and was frequently designated to certain social groups, it did not counteract the main segregation trends.

In the late 1980s and early 1990s, the issue of residential socio-ethnic segregation regained attention in the academic and political arenas of the US and Northern Europe. The economic crisis and the restructuring of economic processes begun in the mid-1970s has contributed to the isolation and de-structuring of many families whose members became involved in cycles of long-term unemployment, socially deviant behaviour and illegal practices (drug trafficking, petty crime, etc.), mostly concentrated in inner city quarters (where ethnic minorities are over-represented) of the Northern European and North American metropolises (Mingione, 1995; Massey and Denton, 1993).

Initially this group, experiencing high exclusion levels, was designated as the underclass in the research literature, especially by those authors who considered economic restructuring of city centres (decline in manufacturing employment, increasing suburbanisation of job vacancies, expansion of the unskilled service sector) the key feature in the process that generates new poverty and increases socio-economic polarisation in cities (Wilson, 1987). The notion of an underclass was subject to criticism (Mingione, 1995; Kempen and Özüekren, 1998) and has been progressively replaced by the concepts of ghettos of the poor or ghettos of the unemployed (Wilson, 1997; De Jong and Verkuyten, 1996), which simultaneously express the specificity of the new situations of social deprivation and its spatial dimension.

As far as US cities are concerned, the work of Massey and Denton (1993) offered residential segregation or hyper-segregation of the black population in American inner cities (with index values over 70 in 100) as a major explanation for their lack of opportunities and their disadvantageous social position. According to these authors, the black American ghetto, a notion that will be discussed later, is the product of the interaction between institutional discriminatory practices, physical urban policies and the action of the private housing market, which push the black Ameri- 
can population to marginal and derelict residential areas.

Northern European researchers try to stress the originality of the European cases (lower segregation indices, the role of public sector housing, the ethnic mix of neighbourhoods and the higher degree of consolidation of the urban centres in the peaks of international immigration), and frequently mention that the Northern American theories of ethnic segregation should not be applied directly to European cities (Kempen and Özüekren, 1998; Musterd et al., 1998). However, American theories are frequently taken as references, a situation that leads researchers like De Jong and Verkuyten (1996) to say that most of the studies about ethnic relations in the European inner cities are supported by the ecological models inherited from the Chicago School or by the relationship between established residents (who occupy an advantageous position) and strangers (frequently, subordinated ethnic minorities) attributed to Elias and Scotson.

Although accepting the similarities between the processes occurring in North American and Northern European cities, and the fact that spatial segregation contributes to the deepening of the social exclusion of vulnerable groups both in Northern European and Southern European metropolises, we should note the following differences between the aforementioned societies. The social value of a job, especially the social meaning of employment, is higher in the Northern European countries, especially those embedded in a Protestant culture. This means that unemployment is associated with stronger potential social devaluation (despite the effectiveness of social security systems), namely because the mobilisation of solutions like clandestine work or family support systems are less compatible with the working culture of countries like the Netherlands or the UK. In contrast, Spain has experienced official unemployment rates of over $10 \%$ for more than 15 years but there has not been a generalisation of discourses about the underclass or the ghettos of the poor. In Portugal, the researches of Almeida (1993) and Ferreira (1993) clearly show the role of family networks and resources in crises. Despite the erosion of the traditional role of the family in Southern European societies, this institution still has a 'pillow effect', contributing to the reduction of potential social tension. Furthermore, the significance of social institutions related to the Catholic church in countries like Italy, Spain and Portugal, replacing the Welfare State in some functions, is another specific element.

\section{THE NORTH-SOUTH DIVIDE IN THE RESIDENTIAL SEGREGATION OF WESTERN EUROPEAN METROPOLISES}

Ghetto is a word of Italian origin that was primarily associated with the Jewish segregated quarter in sixteenth-century Venice. According to perspectives based in AfricanAmerican experiences, a ghetto is an area where the population belongs to the same ethnic, religious or racial group and the majority of this group live in this area (Van Amersfoort, 1990; Peach, 1996). However, this strict concept of ghetto has been discussed by authors such as Peach (1996: 217), who distinguished between the above-mentioned 'real' ghetto and a 'lighter' form of ghetto (the reputational or Irish ghetto), which corresponds to an area where a certain population group is concentrated and over-represented, without constituting the statistical majority. Besides these questions, the same authors stress that a ghetto has an institutional dimension, that is, the spatial concentration is the result of factors external to the decisions and wishes of the segregated group. This 'coercion' element is crucial to distinguish between active (free choice prevails over external constraints) and passive segregation (external constraints prevail over group decisions) (Malheiros, 2000), and also to understand why the spatial concentration of some groups may be considered negatively. On the one hand, the institutional dimension of ghettos points to the limited opportunities of some population groups while choosing a home. On the other hand, segregation and the stigmatisation of some areas may hinder the social participation possibilities for its residents (Kempen and Özüekren, 1998: 1633).

Taking the notion of the ghetto as a reference point, several researchers ${ }^{5}$ note the absence of the hyper-segregated 'real' ghettos in Northern European cities, although many residential 
concentrations can be classified as reputational ghettos. Not only are the segregation indices lower than in their US counterparts, but the levels of ethnic mix are higher.

Although accepting the absence of a single spatial organisation model of the migrants and ethnic minorities in Northern European cities, as underlined by Musterd et al. (1998), we hypothesise that the differences between the Southern European and Northern European metropolises are greater than the internal dissimilarities of these groups. Paris is probably closer to the Southern European model, because the poor and ethnic minorities are more concentrated in the first and second peripheral 'crowns' than in the inner city (Guglielmo, 1996).

In addition to the question of the peripheral residential position of immigrants in Southern European cities, the other idea associated with our hypothesis corresponds to the identification of lower levels of segregation.

\section{A Preliminary Typology}

Using six indicators of foreign populations or the relationships between foreigners and nationals, ${ }^{6}$ we have established a first typology ${ }^{7}$ of 22 Western European cities in respect of immigration. Data were extracted from the EU Urban Audit Database which provides relatively comparable information for 58 metropolises in 14 member states. ${ }^{8}$ The population definitions for the different cities are all based on nationality criteria (nationals, EU foreigners, non-EU foreigners). However, problems stem from this because different countries have different nationality policies - while the Nordic countries and the Netherlands have relatively high annual rates of naturalisation, Southern European countries are clearly less generous in this procedure.

From the 58 cities included in the database, only 19 metropolises (with 500,000 or more inhabitants or included in a conurbation with a population over 1 million individuals) - with available information for six indicators - were selected for analysis. Three cities with populations below the defined thresholds were added (Strasbourg, Luxembourg and Geneva) due to their important economic and/or political international role. It is noteworthy that data for Luxembourg, Geneva and Oslo were collected directly from national sources, although an effort was made to approach the specific criteria used in the Urban Audit Database.

If we split the tree-diagram at a distance of 120 units (Fig. 1), we obtain three groups of cities plus three isolated metropoli:

(i) Group 1 (old urban-industrial core) clusters the metropolises with industrial traditions in Northern Europe (England, Scotland, the Netherlands, Denmark and Northern France) and also Barcelona, the most important industrial city in Spain. In general, these cities have the highest percentages of non-EU foreigners, a situation that points to an early (1960s and early 1970s) and intense process of immigration. The proportion of foreigners in the total resident population is increasing, a situation that uncovers the positive effects of the demographic dynamics of the cities (a contribution to youth renewal and population growth or, at least, to the slackening of decline). Finally, the comparison of the distribution of nationals and foreigners in the central city and in the conurbation shows an over-representation of the first group in the periphery and of the second one in the central city (Table 1).

(ii) Group 2 (Western Mediterranean cities and consolidating migration destinations). This group of cities in Iberia and Southern and Central France also includes Stockholm, an older immigration city which experienced a change in the composition of immigration in the last 15 years (previously dominated by Nordic origins, mainly Finland; nowadays dominated by non-European ones). Helsinki, another city on the periphery of Europe which is becoming more attractive for immigrants, is close to this group although technically outside. The main differences between this group and the first one are the smaller proportion of non-EU foreigners, the importance of indigenous urban demographic growth, and the higher levels of residential suburbanisation of the foreign population

Int. J. Popul. Geogr. 8, 107-134 (2002) 


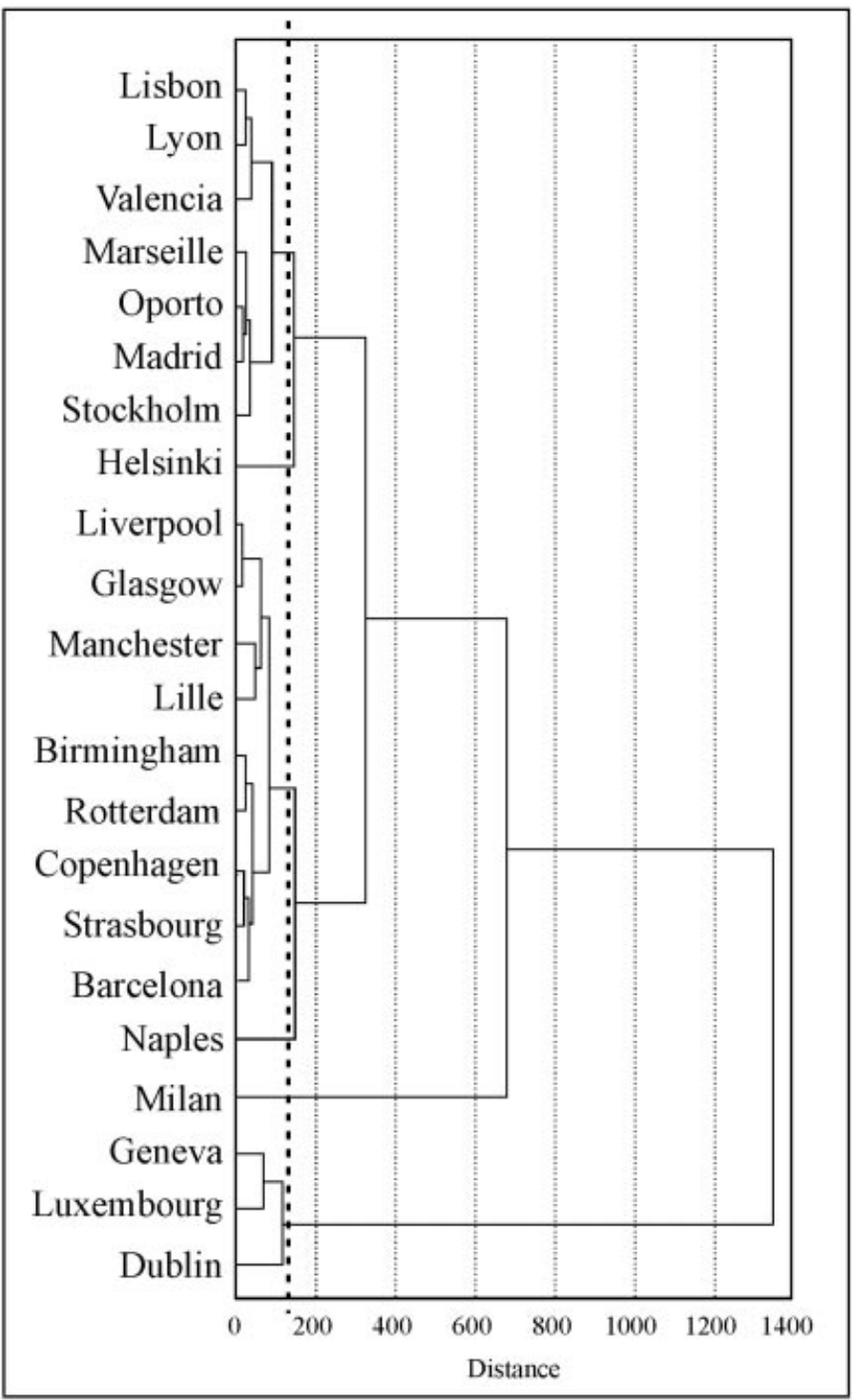

Figure 1. Similarity degree between a set of EU cities considering several indicators of foreign population and migration issues.

(Table 1).

(iii) Group 3 (the small metropolises of European immigration). This cluster is composed of three relatively small cities, in particular Luxembourg and Geneva. The difference between Dublin and the other two is due to its lower proportion of non-nationals (Table 1). Despite this internal distinction, the average values of this group reveal an important presence of foreigners from other EU countries. In terms of the suburbanisation of foreign- ers and nationals, the situation is closer to the case of Group 1 than to Group 2.

(iv) Naples and Milan. Although these cities are considered together, they do not constitute a single cluster, being isolated cases in the tree-diagram. While Milan already has a percentage of foreigners greater than the average of Group 2, this value is very reduced in Naples.

Taking this picture as a departure point, there is evidence to sustain a hypothesis 


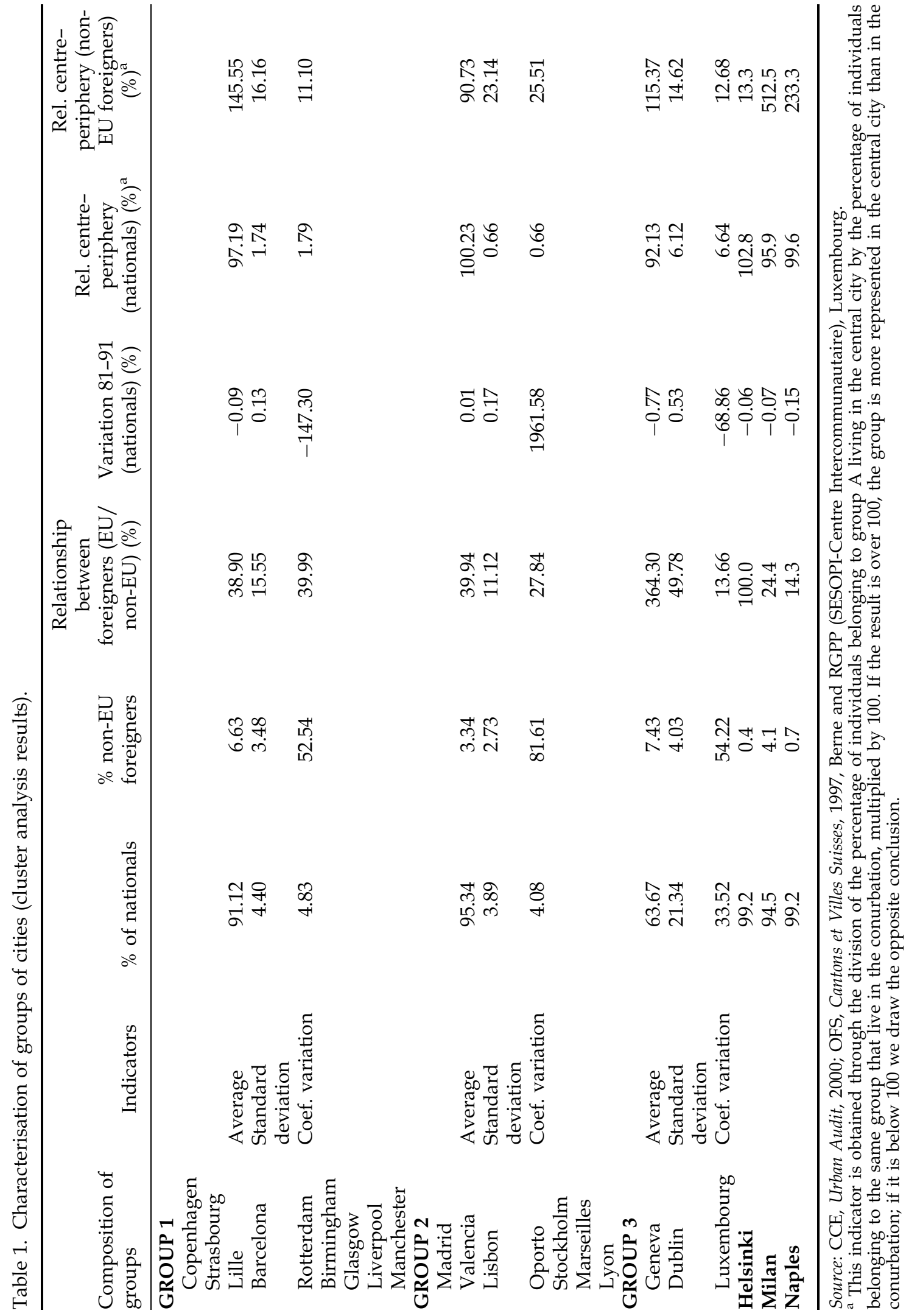


concerning the distinctiveness of the spatial location patterns of the foreigners in Southern European cities, at least in the Western Mediterranean. However, it is important to place these cities in the broader context of new cities of immigration.

\section{Migration Features - The Search for Commonalities in the Southern EU Countries}

The hypothesis of the originality of Southern European ethni-cities is sustained by the context of recent international migration (1980s and 1990s), which is still quantitatively smaller than that registered in the metropolises of the 'old core'. Besides this quantitative dimension, some researchers (King et al., 1997; BaldwinEdwards, 1998) have tried to identify the factors that unify immigration in the southern states of the EU and differentiate it from the processes that took place in Northern Europe. Amongst these, the following have a major influence on the organisation of the migrants' residential space: the relevance of non-documented migrants; the diversity of immigrant populations; the post-industrial character of migration; and the relationship between immigrants and the informal labour market.

The last two factors are related to the processes of labour market insertion, and point to the concentration of immigrants in metropolitan areas, working in non-manufacturing activities such as personal services, retailing, street vending and construction, often outside the formal economy. As some authors (Baganha, 1996; Ribas Mateos, 1999) have demonstrated, Southern European states are characterised by a dynamic culture of economic non-regulation that leads to high levels of labour market informality in some activity branches (personal services, construction, etc.), where immigrants tend to be over-represented (Werth and Korner, 1991; Baganha et al., 1999; Frangouli-Papantoniou, 1999).

The majority of immigrants in clandestine activities undertake low-skilled tasks and face employment irregularity. As far as the residential market is concerned, this curtails the immigrants' choices, not only due to low salaries but also due to irregular incomes -which cause difficulties in paying monthly rents-and the geographical mobility of 'work places' in branches like construction and street vending. Consequently, they tend to rely on informal (and sometimes ethnicised) segments of the housing market. Transient migrants frequently opt for transitional solutions that involve renting rooms in cheap hotels of the inner city or in the flats of relatives and conationals. Irregular migration status also influences residence because access to the formal housing market requires the fulfilment of certain formalities (having documents, a bank account, etc.) that can normally only be achieved by legal or registered migrants.

Finally, the diversity of immigrant populations (King, 2000) is a feature that contributes to the potential reduction of spatial segregation based on ethnicity, and especially to preventing the development of 'institutionalised' ghettos. Although the process of spatial clustering of immigrant groups is strongly affected by their limited access to some housing market segments (income levels, informational barriers, conditions for benefiting from public housing, and so on), there is also a tendency to re-cluster in destination places based on intra-group factors such as the provision of self-support or shared sociocultural backgrounds in strange and often hostile societies. The presence of a wide range of migrant groups in the same city makes more complex the potential development of a corresponding number of different spatial clustering strategies which, besides ethnicity, are also affected by factors like social identity, age or household composition (Kempen and Özüekren, 1998).

A caveat must, however, be added to this last assumption. By stating that greater diversity in the immigrant populations induces a reduction in segregation indices in Southern European cities, we are not denying the existence of mixed neighbourhoods in the metropolises of Northern Europe. As stressed by Kempen and Weesep (1998) for Dutch cities, ethnically mixed neighbourhoods are more the rule than the exception. This demonstrates the strong effect of housing market constraints over the choices for all disadvantaged groups, leading to their spatial concentration. 


\section{Distinctive Elements in the Cities of the South}

Besides the distinctive immigration features of contemporary Southern Europe, the internal organisation dynamics of the urban centres of the Northern Mediterranean also shape the spatial options of ethnic minorities and foreigners. Here we emphasise four issues: sociospatial patterns of location, regulation systems related to planning and the housing market, housing market structures, and the temporalities of internal migration.

Authors like Leontidou (1993) and Banata Salgueiro et al. (1997) point to the existence of lower levels of social segregation in Mediterranean cities, stressing that they are characterised by a higher internal social mix. Due to the late development of industrial capitalism (Mingione, 1995), and of a formal urban planning culture, the cities of the South have experienced more limited socio-ethnic and functional segregation. The relative exceptionalism of urban regulations has contributed to limiting social clustering, leading the cities of the South and their suburban extensions to more 'disorganised' patterns, in both urban and social terms.

The lack of strong mechanisms of urban control enabled the development of clandestine housing and slums, especially in the peripheries of large cities. The substantial waves of internal migrants from rural areas to the main urban centres in the 1950s and the 1960s. ${ }^{9}$ (King et al., 1997) frequently lacked financial resources to buy a house in the formal market, and adopted the strategy of establishing themselves in self-constructed houses and shacks in the suburban rings.

During the last three decades, national and local authorities have tried to regulate these situations and several policy solutions were implemented, including the provision of urban infrastructure, the legalisation of clandestine quarters and the relocation of population in to public housing combined with the demolition of shanties. This has occurred at different speeds and is more advanced in Spain ${ }^{10}$ and especially in Italy, where such slums have almost disappeared. In Portugal the number of illegal dwellings and physically degraded neighbourhoods is more significant.
Despite efforts to improve urban living conditions, to implement effective urban plans and to legalise the more or less spontaneous residential areas, a culture of non-regulation developed and the informal housing market has functioned, especially where market demand was dynamic. The era of major internal migration has certainly passed, but the subsequent arrival of foreign migrants has contributed to feeding not only the informal housing market, but also the cheaper levels of the formal housing supply.

Informal housing in the peripheries is not the only option for immigrants in the Southern European cities, but specific features frequently restrict them to this. There are barriers to access to social public housing, starting with legal restrictions that have only progressively (and still partially) been removed in recent years. Besides, the public housing stock is limited in Southern Europe compared with most Northern EU states. ${ }^{11}$ Finally, the Southern European housing market has been historically dominated by 'buying' rather than renting, which has limited immigrants' access to the formal housing market due to difficulties in securing long-term credit.

Of course, the traditional letting and subletting strategies developed in the old deprived quarters of the inner city are still active. They were used by internal migrants and, to a certain extent, they are still used by immigrants - in Barcelona, Madrid, Milan or Athens we can find poor foreigners living in the inner city (King and Iosifides, 1998; Tosi and Lombardi, 1999; Lazaridis and Psimmenos, 2000). However, the idea of the city centre as a geographical entry to the city is, in our view, distorted. Nowadays the entry doors to the city are mainly non-places-following the arguments of Marc Augé (1994) - places that do not have strong historical, relational or identity meanings. Airport lounges and motorways/ service stations are two typical examples and, to a certain extent, the new lounges of modern railway stations. City centres may be the entrance doors to the social city for newcomers because they provide an identified geographical point, a meeting place where people and information circulate. However, this requires visiting rather than living in the centre. If there is an active cheap housing market in decaying 
Original features in the spatial organisation of ethnic minorities in the Southern European metropolis

\section{ORIGINAL CITY STRUCTURES}

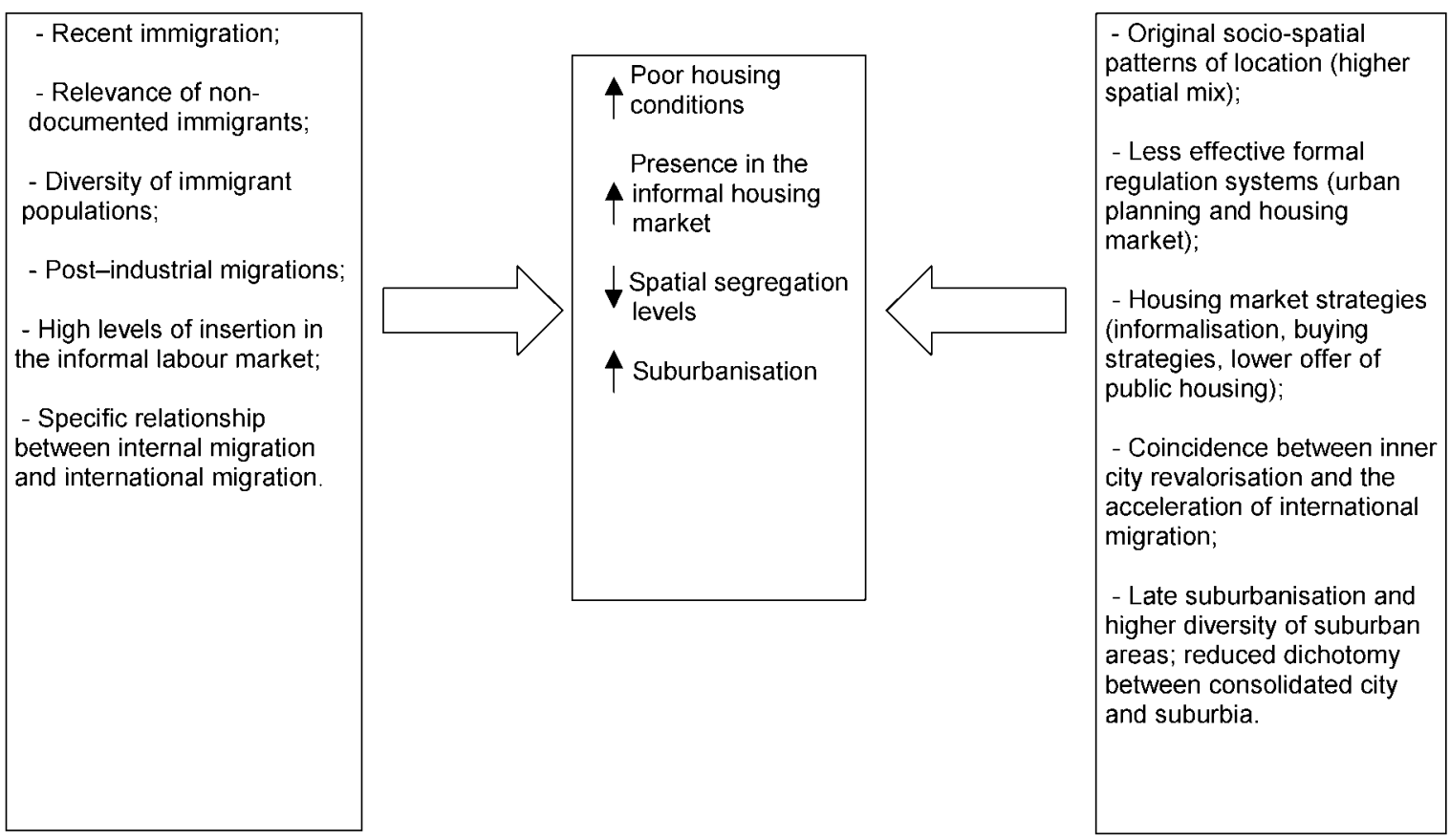

Figure 2. The originality in the spatial position of immigrants in Southern European metropolises.

areas of the city centres, immigrants may find accommodation there. However, as shown by Tosi and Lombardi (1999) in Milan, the city centre is frequently a transition place, where immigrants remain until they have the means (financial, or at a different stage in the life cycle) to find better accommodation elsewhere.

\section{Outcomes: Informal Housing, Lower Segregation Levels and Higher Suburbanisation?}

Figure 2 summarises the features we have discussed, clarifying the links between the different elements. With a subset of more detailed data for eight cities (four in Northern Europe and four on the Western side of the Mediterranean) we have tried to increase the empirical sustainability of our hypothesis. Because our focus is on the Southern European metropolis, and we were only able to gather information for four cases, we also included four Northern European metropolises, corre- sponding to Group 1 of the typology represented in Fig. 1, ${ }^{12}$ for reference purposes.

Before discussing the empirical results, it is important to underline the limitations of this comparative analysis, especially when utilising databases referring to metropolises in several European countries. The main limitation is the lack of systematic information about immigrants and ethnic minorities at the intraurban level. Whereas the Urban Audit Database used in the overview was constructed after a careful filtering of several national sources, the intra-urban level of analysis is more problematic because the information comes from different national databases which were subjected to specific forms of statistical treatment in order to overcome some of the differences that limit comparability.

The first concern is the criteria used to classify the population groups of foreign origin in the different countries. In Rotterdam, the classification is based on the geographical origin of the individuals or their parents, ${ }^{13}$ 
whilst in the Southern European cities and Brussels the definition relies on simple nationality criteria. Finally, in English metropolises the information gathered in the census of 1991 follows specific ethnic criteria for the nonEuropean groups, all other individuals being classified as 'white' (Peach, 1996).

At first sight, these definitional differences pose severe limitations to cross-comparative analysis. However, these statistical classifications do express how groups of foreign origin are perceived by the socio-political systems in each country. Because the spatial segregation of minorities of foreign origin is associated with socio-ethnic features, in countries with relatively generous naturalisation policies, like the Netherlands, ${ }^{14}$ the use of nationality criteria would be limiting, excluding a large proportion of the foreign-born population. Besides, people born in the former Dutch and British colonies have benefited in the past from advantageous naturalisation criteria. Bearing these features in mind, it is probably more relevant to use databases that respect the specific classifications of the 'other' used in each country, rather than to use an artificial common classification (based exclusively on nationality, for instance) which, in certain cases, would exclude large proportions of the populations of foreign origin.

A second type of problem relates to the different sizes of the metropolises and the size and number of spatial units in each metropolis. In some cases the data refer to metropolitan areas (defined according to different criteria), whereas in others they are for cities. For instance, the Metropolitan Area of Madrid, with 4.5 million inhabitants, is 11 times larger than the city of Manchester. If we had only used cities (or metropolitan areas), the problem would be mitigated but by no means solved. For instance, not only are the cities (municipalities) of Barcelona and Milan three to four times larger than the cities of Manchester or Rotterdam, but they also have a larger population than the region of Brussels-Capital, which encompasses several municipalities. Bearing this in mind, the choice of whether to use the metropolitan area or the administrative city depended on the geographical reference base of the data and on how these data were internally disaggregated.
In terms of spatial disaggregation, several authors (Peach, 1996; Wong, 1997) have discussed the influence of the demographic dimension of the groups in the analysis and also of the size of the spatial units used to calculate segregation indices. Synthetically, we may say that the value of segregation indices increases when the dimension of the geographical units of analysis is smaller because '... segregation measures are functions of the internal homogeneity of the enumeration units; and units smaller in area tend to include observations very similar to each other in many instances' (Wong, 1997: 135).

It is important to take into consideration this statistical regularity when comparing the results of the segregation indices obtained for the eight cities, because of differences in the average size of the internal spatial units (Table 2). This is especially important in Madrid and Milan, which have larger units than the other metropolises. However, although this may decrease the values of the segregation indices in these two metropolises, this does not substantially change the overall results. In fact, if we take into consideration another statistical trend associated with segregation indices (a tendency towards increased values where population subgroups are very small; Peach, 1996), we could expect higher segregation values in Southern European metropolises, but this only occurs in the case of Barcelona which has two very small groups of non-EU foreigners. In summary, we believe that technical limitations should be taken into account when interpreting the results of the analysis, but they do not invalidate the trends that are identified. Moreover, the technical procedures adopted to improve comparability (increasing the average size of the internal units of some metropolises through spatial aggregation procedures, direct calculation of segregation indices, ${ }^{15}$ choice of major foreign/ ethnic groups as a reference for calculations) provides a good picture of the dominant patterns.

The housing problems of immigrants and their involvement in the informal residential market are evident in several Southern European metropolises. This is not a new situation because immigrants in the major cities of Northern Europe experienced housing 
Table 2. Segregation indexes for significant minority groups in selected European cities.

\begin{tabular}{|c|c|c|c|c|}
\hline Metropolis & Indices & $\begin{array}{l}\% \text { in total } \\
\text { population }\end{array}$ & $\begin{array}{l}\text { Number of internal } \\
\text { spatial units }\end{array}$ & $\begin{array}{l}\text { Average population } \\
\text { per unit }\end{array}$ \\
\hline Barcelona & - & - & 37 & 40,779 \\
\hline EU foreigners & 35.0 & 0.52 & - & - \\
\hline Moroccans & 56.8 & 0.23 & - & - \\
\hline Peruvians & 22.9 & 0.20 & - & - \\
\hline Filipinos & 65.4 & 0.13 & - & - \\
\hline Lisbon & - & - & 149 & 16,593 \\
\hline EEC + North & 37.1 & 0.44 & - & - \\
\hline \multicolumn{5}{|l|}{ American foreigners } \\
\hline Cape Verdeans & 43.3 & 0.56 & - & - \\
\hline Brazilians & 30.7 & 0.18 & - & - \\
\hline Africans (total) & 34.8 & 1.10 & - & - \\
\hline Madrid & - & - & 45 & 101,707 \\
\hline EU + North & 33.1 & 0.53 & - & - \\
\hline \multicolumn{5}{|l|}{ American foreigners } \\
\hline Latin-Americans & 20.2 & 0.65 & - & - \\
\hline Peruvians & 22.1 & 0.19 & - & - \\
\hline Moroccans & 27.3 & 0.26 & - & - \\
\hline Milan & - & - & 20 & 65,838 \\
\hline Egyptians & 17.1 & 0.62 & - & - \\
\hline Filipinos & 19.7 & 0.57 & - & - \\
\hline Chinese & 34.8 & 0.29 & - & - \\
\hline Moroccans & 22.1 & 0.27 & - & - \\
\hline Birmingham & - & - & 39 & 24,640 \\
\hline White & 58.4 & 78.50 & - & - \\
\hline Black Caribbean & 41.7 & 5.90 & - & - \\
\hline Indian & 62.1 & 13.50 & - & - \\
\hline Brussels & - & - & 24 & 39,187 \\
\hline EU foreigners & 18.7 & 14.69 & - & - \\
\hline Turks & 59.0 & 2.22 & - & - \\
\hline Moroccans & 42.6 & 7.77 & - & - \\
\hline $\begin{array}{l}\text { Asians + Africans } \\
\text { (total) }\end{array}$ & 30.6 & 12.85 & - & - \\
\hline Manchester & - & - & 33 & 12,269 \\
\hline White & 45.7 & 87.40 & - & - \\
\hline Black Caribbean & 50.7 & 2.90 & - & - \\
\hline Indian & 51.0 & 5.40 & - & - \\
\hline Rotterdam & - & - & 55 & 10,838 \\
\hline Dutch & 32.7 & 61.15 & - & - \\
\hline Surinamese & 29.9 & 7.33 & - & - \\
\hline Cape Verdeans & 47.0 & 2.09 & - & - \\
\hline Turks & 51.9 & 5.67 & - & - \\
\hline Moroccans & 47.2 & 3.71 & - & - \\
\hline
\end{tabular}

Sources: Compiled and treated from statistical data bases coming from the 1991 Censuses for Birmingham, Manchester and Lisbon; 1996 Population Patterns of the Comunidades Autonómicas of Madrid and Barcelona; Tosi and Lombardi (1999) for Milan; Centrum voor Omderzoek en Statistiek te Rotterdam 1993 for Rotterdam and statistics of the Region of Brussels-Capital (1998).

problems. However, the specificity of the housing market as well as the features of the present post-industrial migration lead to a search for new types of responses which should bear in mind, but not replicate, Northern European models. 
Table 2 shows lower proportions of foreigners and ethnic minorities in Southern European metropolises and lower levels of segregation in these cities, with the exception of Barcelona. Whereas segregation indices of over 50 are observed in the Northern European cities (and in Barcelona), the Southern European metropolises have values under 40 or even 30. This seems to confirm the tradition of more reduced levels of spatial segregation which, in the past, were associated with the social dimension but now also incorporate an ethnic one. Social segregation has become socio-ethnic segregation in the metropolises of the South, but the images of an urban space patterned according to ethnic and social lines are apparently less clear than in the cities of the North. Actually, some authors (Barata Salgueiro, 1997) point to the gradual replacement of the (lighter) segregated city model by the socalled fragmented one in the Mediterranean cities. This fragmentation of the urban tissue is associated with the settlement of small functional and/or social enclaves that are in discordance with the surrounding urban environment.

Nevertheless, the growing presence of ethnic minorities introduces a new dimension of segregation that in future may distort these images of lower levels of segregation and the emergence of fragmentation processes. The over-representation of immigrants in several areas where urban physical problems (shanty houses, poor quality housing facilities) match social ones (unemployment, group tension, illegal activities like drug trafficking and consumption) obliges the authorities of the Southern European cities to incorporate the ethnic dimension in their targeted programmes for problem areas (national and municipal ones, and those supported by the EU within URBAN or LIA partnerships).

The other element of the spatial distinctiveness of minorities in the cities of the South relates to the hypothesis of higher levels of suburbanisation. When the 1960s and early 1970s immigrants arrived in Northern European cities such as Brussels or Rotterdam, they encountered a residential context that was marked by the transfer of young middle-class local populations from the old and low-quality dwellings of the inner city areas to new residential suburbia (Kloosterman, 1998). The vacated inner-city flats were frequently occupied by foreigners who were unable to pay high rents and experienced some limitations in accessing public housing (Musterd et al., 1998; Giffinger, 1998). In subsequent decades, there was reproduction of this process in several older inner-city districts. These were particularly marked if these areas were subjected to renovation interventions that led to only limited increases in rents, and where dwellings could be adjusted for residence by the larger families of foreign residents. However, in cities like Amsterdam, a second transition is apparently occurring and immigrants are now settling in the flats vacated in the peripheral quarters built in the 1950s and 1960s, due to the outmovement of the indigenous Dutch population to the outer suburbs. Gentrification processes are also increasing the quality and the attractiveness of some areas of the inner city, leading to an increase in prices which, unlike in the past, limits the access for deprived foreigners.

Despite these recent trends which introduce more complexity into the locational features of the minorities, the following observations can be made in respect of Figs 3 to 8:

(i) Most cities are characterised by a dual spatial distribution of the ethnic groups, which separates the areas where non-EU groups are over-represented from the areas where 'whites' live, be they nationals or foreigners. This pattern is weaker in the cities with lower segregation levels like Madrid or Milan, and stronger in the cities of the 'old core'. Concerning the Lisbon pattern, the visible contrast is the result of the 'ethnicisation' process of several interstitial peripheral quarters located in the north and west of the Metropolitan Area. Despite this image of ethnically dual cities, especially in the Northern European countries, the 1980s and/or the 1990s were marked by decreases in the segregation indices of several groups of foreigners and ethnic minorities living in London, Rotterdam and Amsterdam

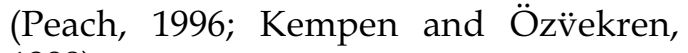
1998). 
(a)

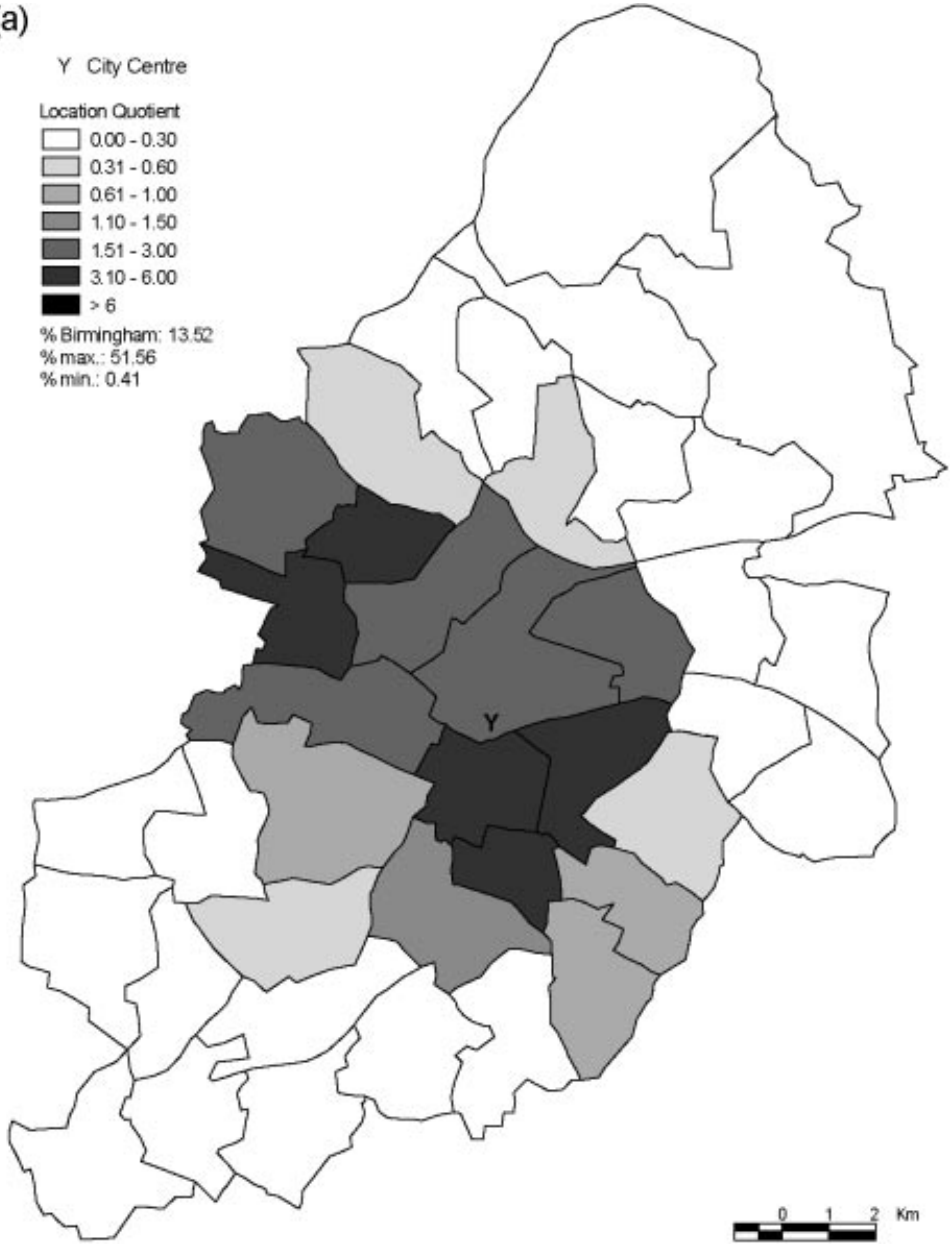

Figure 3. Location quotients of populations in Birmingham, 1991. (a) Indian ethnic population; (b) White population.

(ii) In some Southern European metropolises (e.g. Madrid and Lisbon) the segregation levels of immigrants from developed countries are quite high. Furthermore, their spatial location patterns are close to those of the affluent national classes (Buckley Iglesias, 1998; Malheiros, 2000), which points to the interplay between ethnic identification and social identification. However, the 'institutional' dimension of this clustering is very low or even totally absent due to the wide range of choices available to these populations, especially if we compare them with the groups from Asia, Africa and Latin America.

(iii) The comparison of the maps of Rotter- dam, Birmingham and Brussels (Figs 3 to 5) with the maps of Lisbon, Madrid and Milan (Figs 6 to 8 ) points to a higher degree of relative suburbanisation of the non-EU foreigners in the second group of cities. As far as Southern European cities are concerned, the depopulation of central areas has been more limited than in the Northern European metropolises, despite ongoing tertiarisation processes. In the 1950s and the 1960s, some internal migrants found residence in inner-city areas, but a number of middle-class families maintained their residences close to the city centres (Leontidou, 1993). Although this weaker depopulation process, and the contemporary immigration 


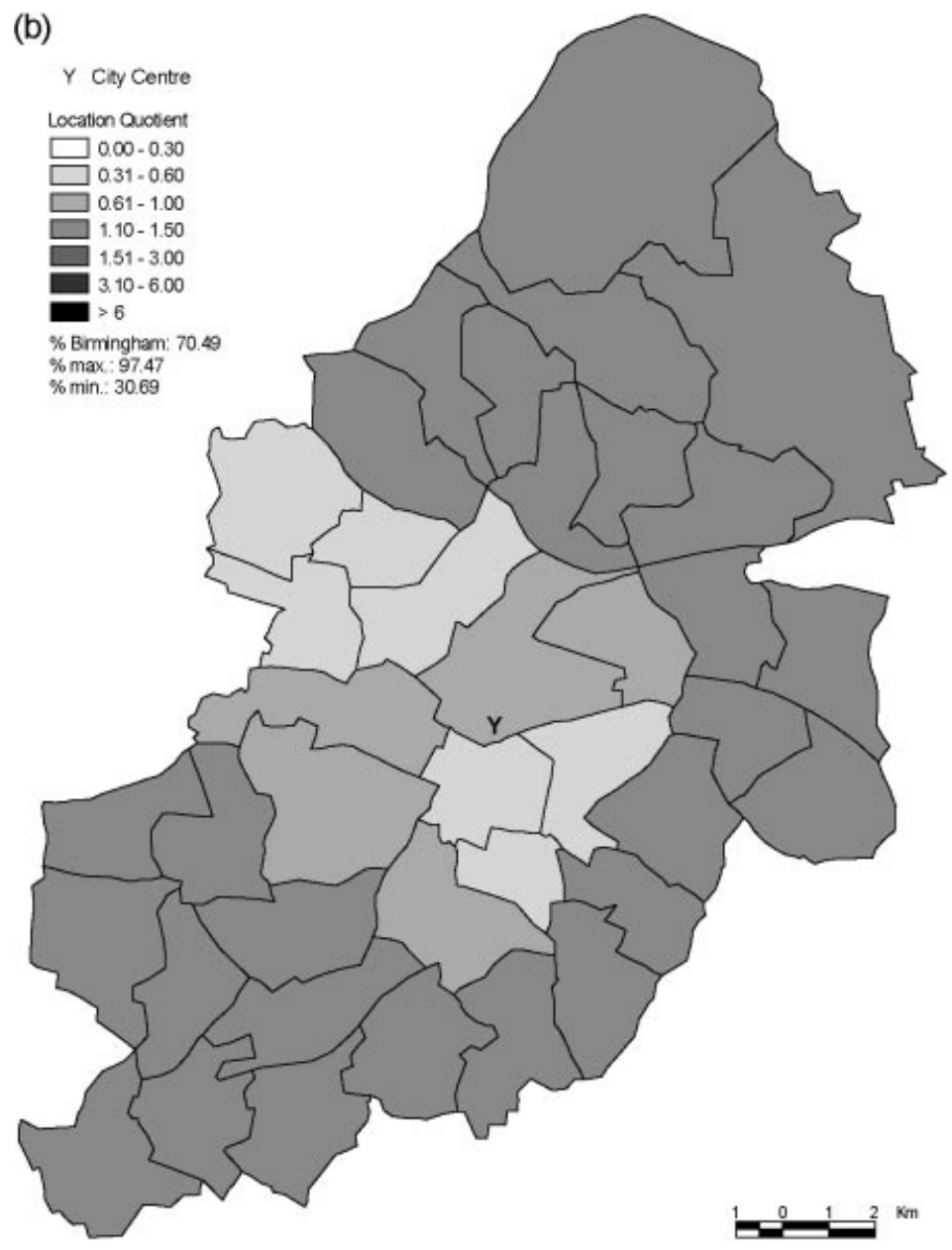

Figure 3. Continued.

wave, largely coincide in time (from the second half of the 1970s onwards), there were limits to the possibilities of finding a house in the inner city, especially in the case of populations with lower resource levels. Firstly, the active illegal estate market of the peripheries was (and still is) competing with the inner city, ensuring an alternative for the newcomers. Secondly, the rehabilitation and renewal processes of several city centres, starting in the $1980 \mathrm{~s},{ }^{16}$ led to the economic revalorisation of these areas, making access for ethnic minorities more difficult. Finally, the Northern European transition trend of stepwise suburbanisation of the domestic population was less evident in the Southern European metropolises.
Despite the aforementioned panorama, showing a scattered spatial distribution of immigrants and a higher level of suburbanisation in the metropolises of the South, we can also find examples of over-representation in the inner city. Barcelona is an extreme example, but the same situation can be found in Milan (Tosi and Lombardi, 1999) and Madrid (Buckley Iglesias, 1998) or Athens (King and Iosifides, 1998; Lazaridis and Psimmenos, 2000), especially in the case of some North African, Latin-American and Eastern European populations. However, the firstmentioned authors state that the over-representation of some groups (Filipinos, Peruvians) in inner Milan is associated with the coincidence between residence and workplace (as porters, maids, etc) in the dwellings of 

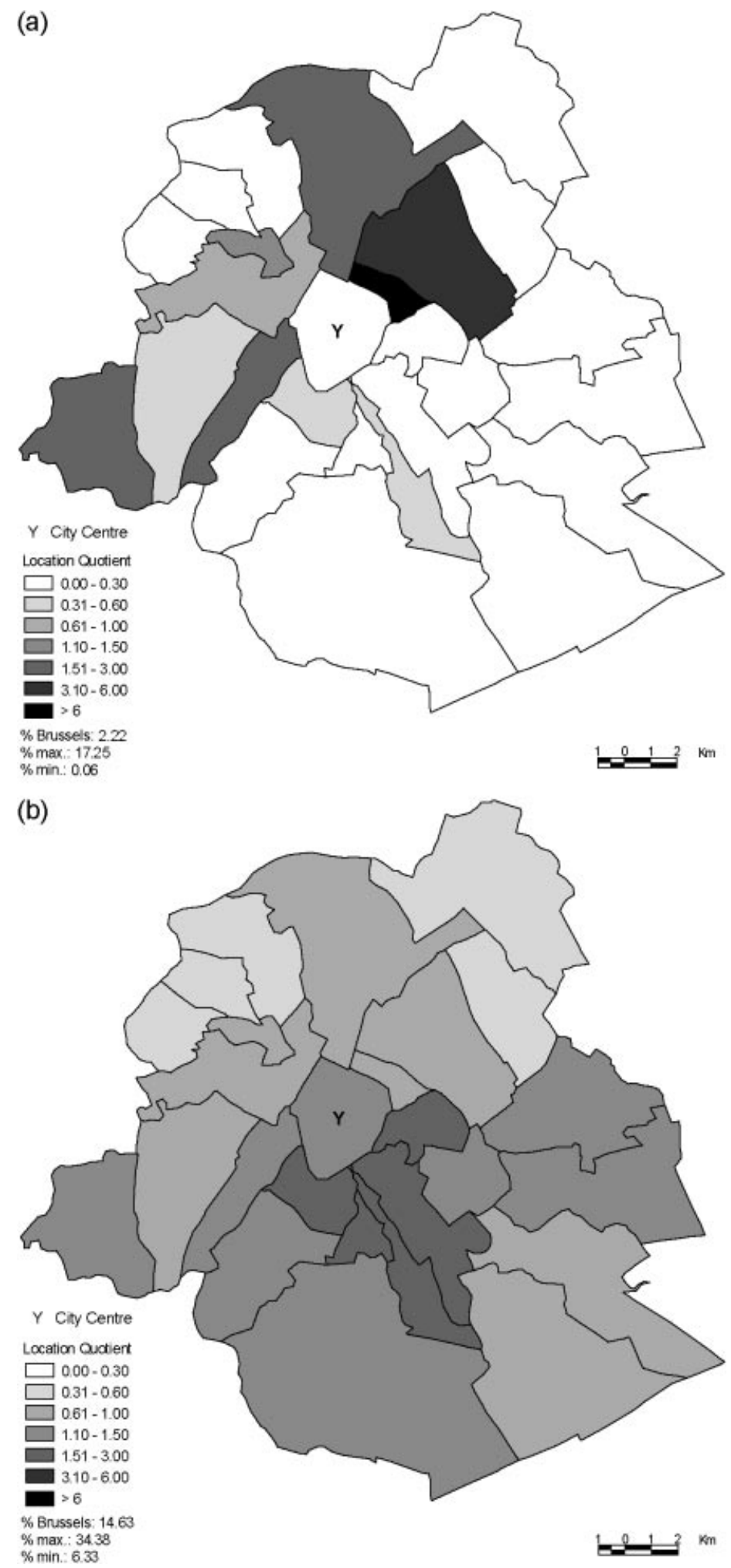

Figure 4. Location quotients of populations in Brussels, 1996. (a) Turks; (b) European foreigners. 


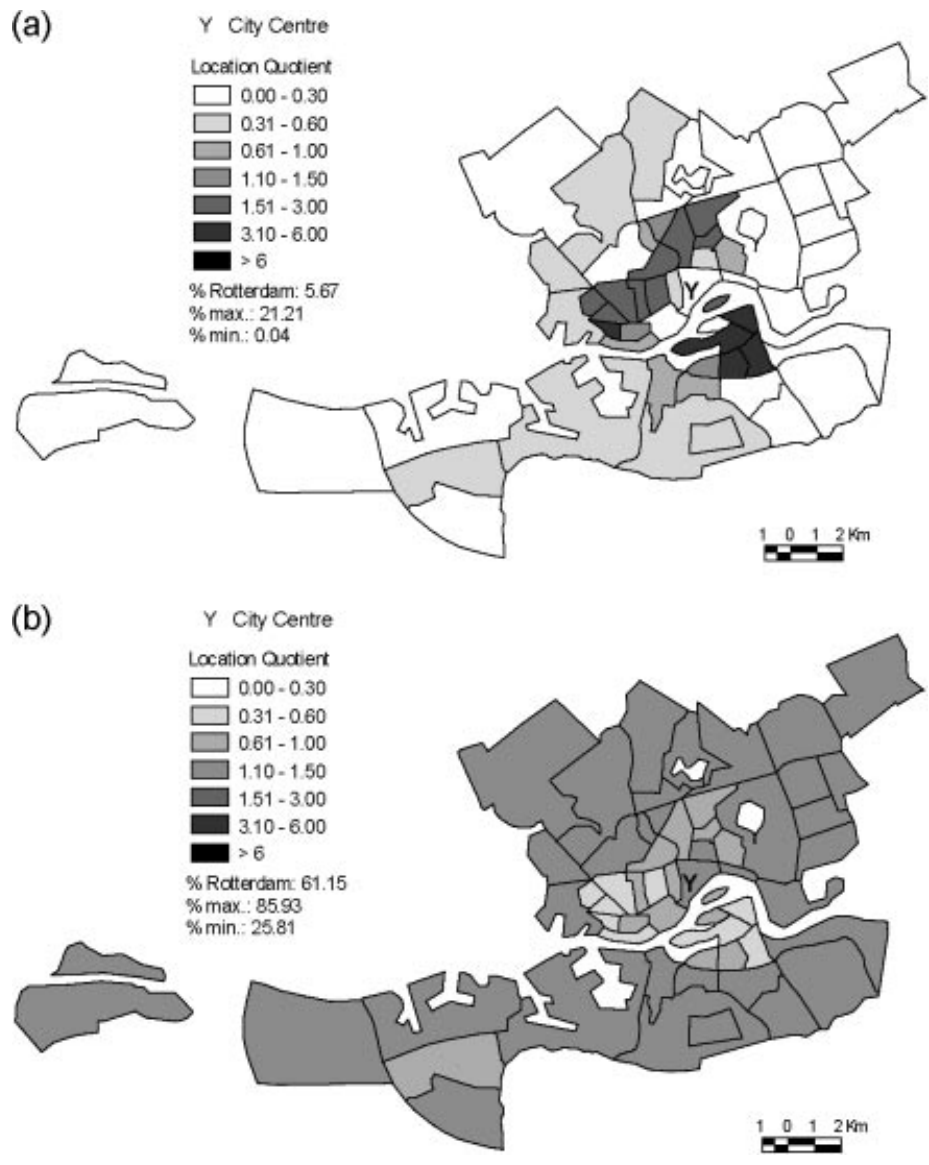

Figure 5. Location quotients of populations in Rotterdam, 1993. (a) Turkish ethnics; (b) Dutch ethnics.

wealthier Italian families. Once their economic and family situations become more stable, the foreigners tend to move to more peripheral areas, joining more recent migratory groups (e.g. Moroccans).

The introduction of the ethnic dimension into the spatial organisation of the Southern European metropolises is not only changing the classic conceptions of these cities but is also leading to urban policy changes, which we discuss in the following section.

\section{URBAN POLICIES IN IMMIGRATION AREAS - LISBON AND ROTTERDAM}

This section discusses policy principles, using the experiences of Rotterdam and Lisbon, which can be considered paradigmatic cases of the divide discussed in the previous sections. While Lisbon is in some ways considered to be representative of the Southern European metropolises, any such reference must be interpreted through the specific features of the Lisbon Metropolitan Area. For the same reason, the experience of Rotterdam, a city with a culture of action that is frequently described as a pioneer in the field of urban and social renewal, ${ }^{17}$ is relevant at the level of action philosophy and policy principles rather than the concrete design of policies.

\section{Background Features}

Is it meaningful to compare the relatively young, organised, flat and brown harbourindustrial city of Rotterdam with the old, disorganised, hilly and colourful metropolis of Lisbon?

In the first case, we have a long tradition of democratic and decentralised government 

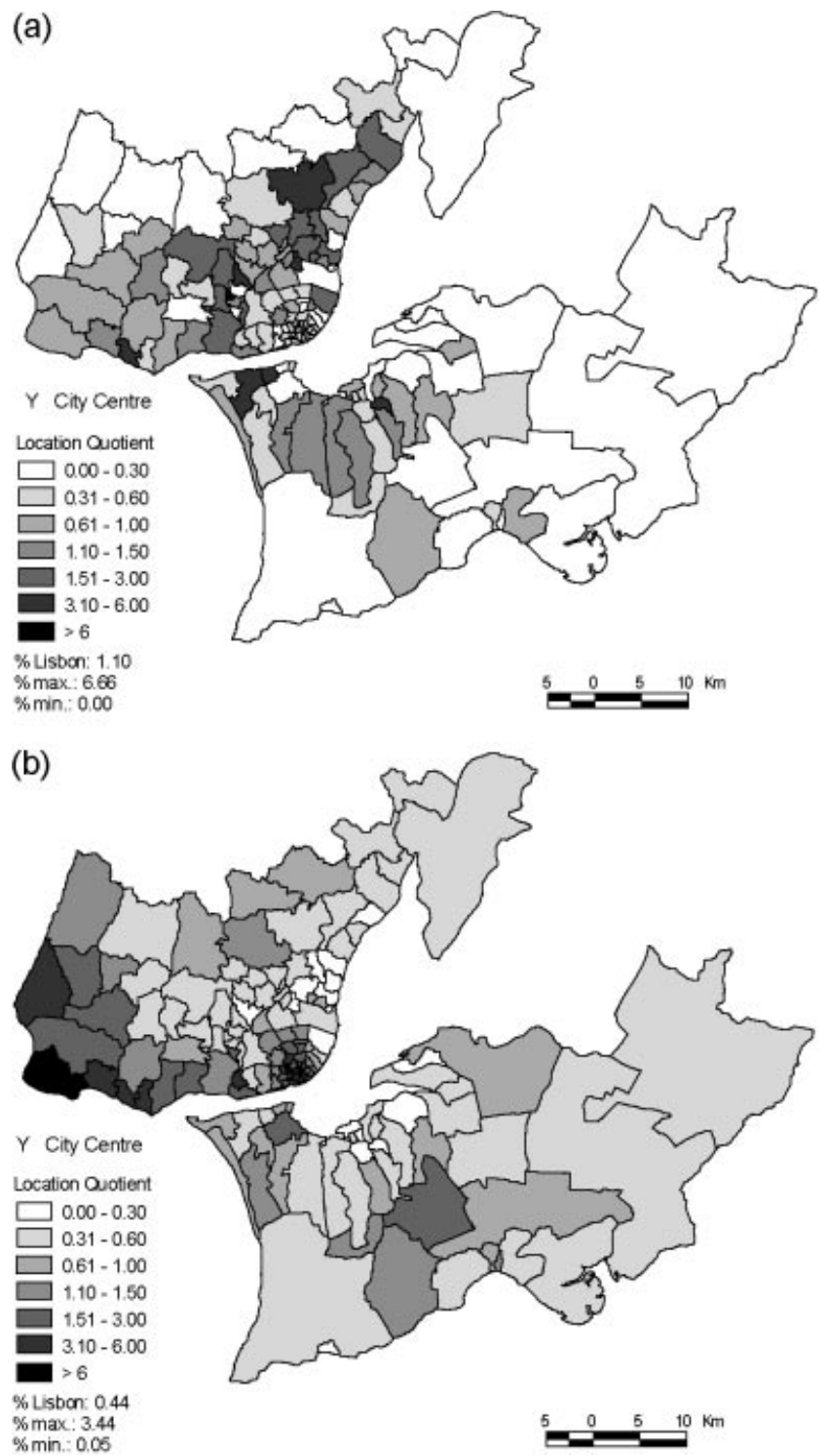

Figure 6. Location quotients of populations in Lisbon, 1991. (a) African foreigners; (b) European and North American foreigners.

bodies with an established tradition in urban planning which, in the late 1980s/early 1990s, incorporated the Dutch notion of social renewal (SCP, 1996: 546; Kloosterman, 1998). In contrast, political decentralisation at the local level and development of an effective urban planning culture only occurred in Lisbon after the Revolution, namely with the 1979 Local Financing Law and the definition of the Municipal Master Plan of 1982 (Fonseca, 1999).

The Netherlands is considered to have a highly regulated welfare state, with state intervention in every key sector, despite recent counter-trends (Musterd and Deurloo, 1997). There is considerable state intervention in the housing sector, leading to significant decommodification, identifiable in the highest proportion of social rented housing amongst the EU countries (Musterd and Ostendorf, 1996; Kloosterman, 1998). In 1997, 58\% of dwellings in Rotterdam were in this sector, despite a trend towards increasing home ownership. In the municipalities of the Lisbon Metropolitan Area, the number of state-owned dwellings is 

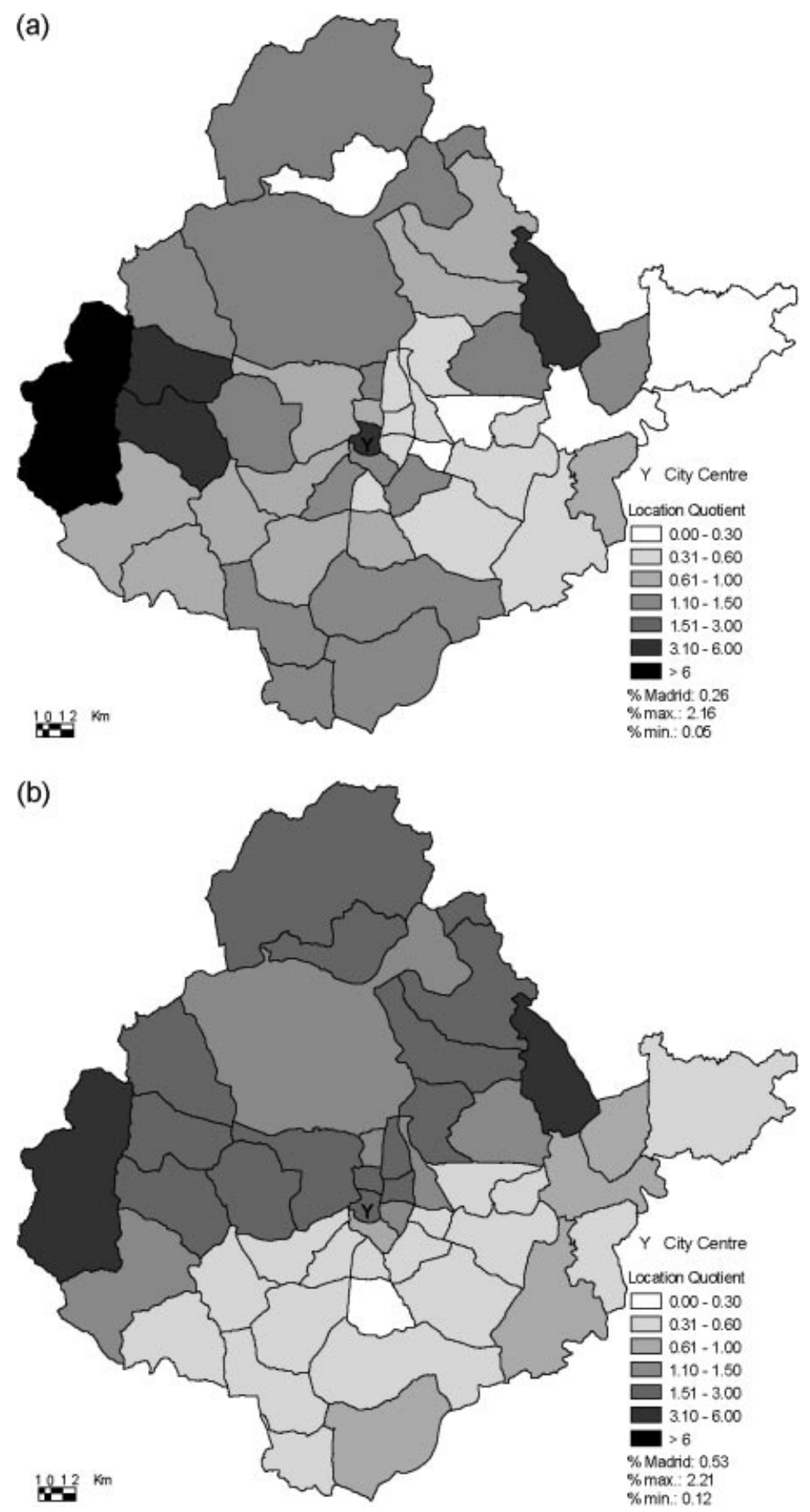

Figure 7. Location quotients of populations in Madrid, 1996. (a) Moroccan nationals; (b) European and North American foreigners.

much lower and several municipalities are trying to sell their housing stocks to the occupiers. However, under the PER (Special Relocation Programme), new flats within the social housing sector are being offered to the inhabitants of former shanty settlements.

In raising these issues concerning democratic tradition at the local level, welfare 


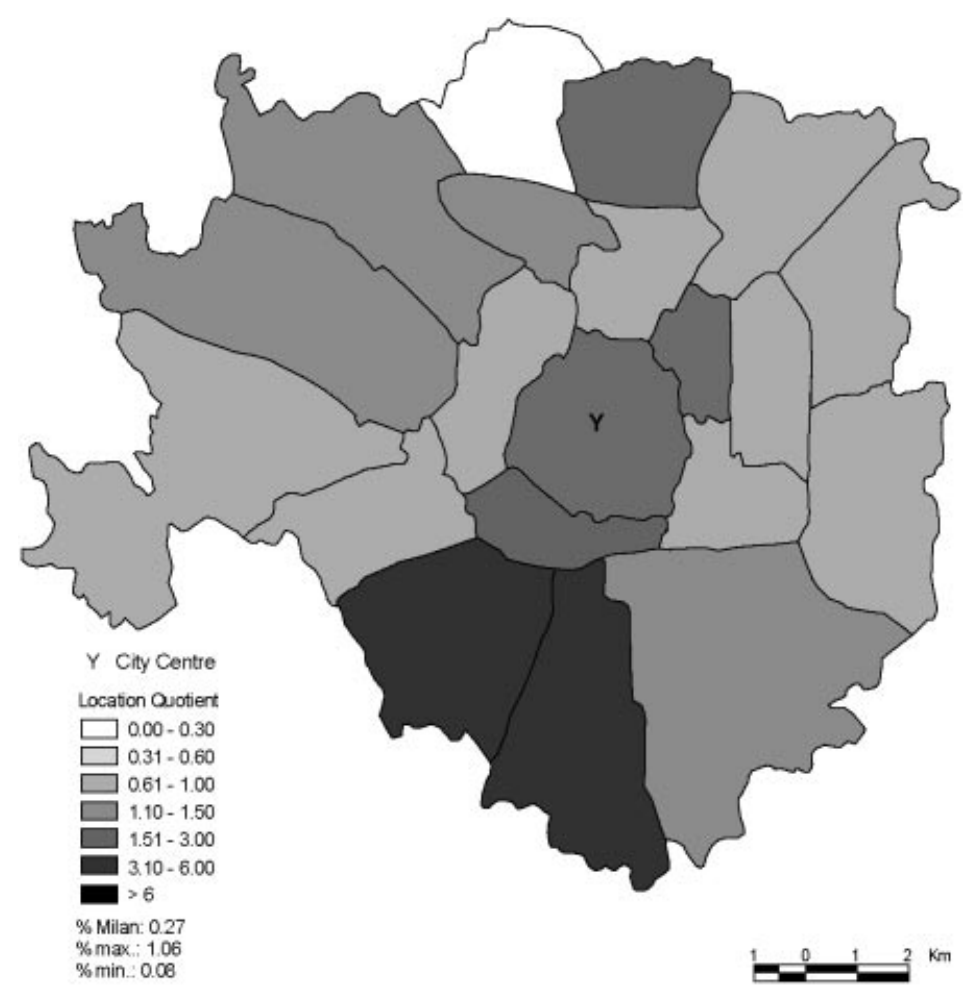

Figure 8. Location quotients of Moroccan foreigners in Milan, 1996.

regimes and intervention in housing and planning, we emphasise the elements that differentiate the local policy frameworks in the two cities. Despite these differences, there are several reasons for developing a comparative approach. The two cities have similar populations (around 600,000 inhabitants) and occupy similar positions in the European urban hierarchy. Moreover, they are both port cities which are implementing processes of urban renewal in their port areas. As far as the Metropolitan Areas are concerned, the differences are greater. While Rotterdam is part of the larger Randstat polynuclear urban structure (over 6 million inhabitants) and does not have a formal metropolitan area, Lisbon is the head of a formal Metropolitan Area with 19 municipalities and approximately 2.5 million inhabitants. In addition, there are differences in the relationship between the major city and the suburban municipalities, which have to be placed within the different contexts of suburbanisation in the two metropolises. The negative effect of the planned suburbs over the city in the case of Rotterdam (the idea that people share the benefits of the centre but not its costs) contrasts with the image of a more favoured dominant city (continued through the municipalities of the western coastal area) and several socially and physically deprived peripheries in the Lisbon Metropolitan Area.

Finally, the immigration stories of the two cities have common traits. The openness introduced by the ports has led to the historical development of cultures of migration and otherness. Concerning contemporary immigration, although Portugal did not receive formal guest-workers in the 1960s, it is possible to identify an early immigration wave of Cape Verdean workers in the late 1960s early 1970s. In fact, the presence of Cape Verdean immigrants is a common feature of Lisbon and Rotterdam, which have the two major concentrations of this population in Europe. In fact, the Cape Verdeans are the first ranked immigrant group in the Lisbon Metropolitan Area (approximately 83,000 people) and the fourth in Rotterdam (around 14,000 people). 
Besides this commonality, there is also similarity in the immigration wave in the second half of the 1970s, associated with the decolonisation processes that took place in Surinam (ex-Dutch colony) and in the PALOP (ex-Portuguese colonies) in 1974 and 1975.

\section{Urban Policies in Ethnic Neighbourhoods}

As far as Rotterdam is concerned, ethnic minorities ${ }^{18}$ cluster in the inner city areas of the first quarter of this century or even the late nineteenth century, located around the relatively new city centre (built after the Second World War), namely west and south of it. In this case, the urban problems are not housing legalisation or the provision of public urban infrastructure, but housing renewal and necessary improvements to living conditions. In some ways, Rotterdam was a pioneer amongst larger Dutch cities in the implementation of an extensive urban renewal process, from the early 1970s, in the nineteenth-century neighbourhoods, being extended afterwards to other urban areas (De Jong and Verkuyten, 1996; Oude Engberink, 1999).

After a first phase of urban renewal that lasted until 1983/1984, and treated Dutch residents as the reference group in the design of plans, largely neglecting the culture and the specific needs of the newcomers, a second phase of urban renewal was implemented which recognised the specificity of the migrants (De Jong and Verkuyten, 1996). This change was in accordance with the principles expressed in the Memorandum of Ethnic Minorities of 1983, which mentioned the need to implement renewal operations in derelict residential areas where ethnic minorities and poor nationals clustered (Niessem and Kruyt, 1997). Immigrants were given the opportunity to participate in neighbourhood organisations (bewoners organisaties) involved in the process, and these started to call attention to the presence of foreigners in the quarters which were subject to renewal. Within this process of increasing the participation of foreigners, they were given the right to vote in the 1980 elections for the submunicipal administrative bodies (deelgemeente). Within this new approach, previous policy hypotheses aiming to disperse ethnic minorities amongst several neighbourhoods (discussed at the local level, although never effectively applied in formal terms) were abandoned (De Jong and Verkuyten, 1996). It was progressively assumed that the question of deprived neighbourhoods, where groups of immigrants clustered, should be considered a problem of physical decay and social exclusion, and not as an ethnic or demographic issue.

Throughout the last 25 years, several blocks and buildings in the inner city have been entirely rebuilt or renovated, as part of an ongoing process. As the urban renewal process incorporated the principle of retaining and offering relatively large dwellings, and as there were no restrictions preventing the access of legal foreigners to the renovated buildings offered by the public housing sector, these people improved their housing conditions but simultaneously maintained their over-representation in the pre-war built areas (Anderiesse et al., 1999).

Therefore, policies up until the late 1980s did not contribute to reducing the segregation levels of the main minority groups in Rotterdam (Kempen and Weesep, 1998). Additionally, the general improvement in the quality of most of the housing did not prevent the socioeconomic decay of certain neighbourhoods, nor did the stimulus to the participation of ethnic minorities lead to a significant growth in their involvement in neighbourhood action or to shared leaderships (Dutch and non-Dutch) in the projects.

In the late 1980s, the social situation in Rotterdam and in the other three major Dutch cities (Amsterdam, The Hague and Utrecht) displayed serious negative signs - unemployment reached very high levels and certain areas of the cities were showing progressive concentrations of long-term unemployment, higher than average levels of criminality and drug trafficking, and large proportions of poor people, many of whom belonged to ethnic minorities (Anderiesse et al., 1999; Priemus et al., 1997).

Within this context, Dutch politicians replaced the concept of urban renewal with the concept of social renewal in the early 1990s. According to Kloosterman (1998), social renewal lasted from 1991 to 1995 and stressed intervention in the non-built elements (inhabi- 
tants, employment, maintenance of public space) of the neighbourhoods. Neighbourhoods became the major targets of social renewal policy that aimed to combine different elements such as job creation, training programmes and social support. Policy implementation should involve residents proactively, breaking away from the traditional top-down approach.

In Rotterdam, this low-level approach, supported by the Cabinet, was in accordance with the policy principles that have been developed since the 1970s, with the emergence of proactive neighbourhood organisations. However, municipal experts and some leaders of ethnic minorities associations stressed two changes related to the 1990s approach: (i) the reduction of the paternalist approach of Dutch social workers and the increasing responsibilities of the ethnic minority associations in the definition and implementation of policies; and (ii) the assumption that cultural backgrounds matter in the definition of policies, and therefore the approach must be flexible enough to incorporate the perspectives of both the Dutch and the minority groups.

This experience of social renewal was the predecessor of the Big Cities Policy (BCP) initiated in 1995, which entered a second stage after 2000. ${ }^{19}$ This policy resulted from a covenant signed between the government elected in 1994 and the political authorities of the four Big Cities. ${ }^{20}$ These presented their demands to the government on a series of crucial topics - employment, investment, safety, integration and administrative organisation-stressing that the Randstaat Big Cities lagged, in several fields, behind the rest of the country and that certain areas of the city were experiencing a process of decline due to the simultaneous development of unemployment, crime, vandalism, high dependence on welfare, and environmental neglect. In 1994, the average income in the four Big Cities was $20 \%$ less than the national average and approximately 30\% below the value registered in suburban municipalities (SCP, 1996:527-44).

In Rotterdam, five deprived areas, all with an over-representation of ethnic minorities, were selected for the implementation of the first stage of this policy, based on three principles, which are in accordance with the basic guidelines of the Big Cities policy: trendreversing policy, integration and support (Anderiesse et al., 1999). A strategic intervention policy for deprived urban areas was created (wijkaanpak-neighbourhood area specific approach) under the general principles of the BCP, which specifically mentions the need to create innovative urban projects that may help to change the image and the living quality of the areas (dS $+\mathrm{V}, 1999)$. It is important to stress the principle of integration, which corresponds to a shift from sectoral approaches to a more comprehensive policy, supported by the so-called three basic pillars: urban (physical), economic and social. This is in accordance with the principles of the EU initiative URBAN, funding projects aiming at the rehabilitation and renewal of derelict quarters in medium and large European cities where immigrants and ethnic minorities are frequently over-represented. The last principle-support-corresponds to the process of establishing good communications between local authorities and populations and also to the development of higher levels of participation among the target groups at the neighbourhood level. This requires decentralisation at the city level (from the Gemeente-municipality - to the deelgeemente - submunicipalities).

Although policies aiming to disperse ethnic minorities were definitely set aside within the framework of new housing policies that shifted from the welfare-state model towards more liberal market strategies, the idea of promoting a social mix at the neighbourhood level (for instance, through the selling of medium/high quality housing estates in the better areas within derelict city centre neighbourhoods) is clearly present. Despite the criticisms of this strategy by authors like Smakman and Musterd (1999), it is important to mention that it may contribute to a gradual reduction in the concentration levels of ethnic minorities, already noticeable in the changes in the segregation indices in the 1990s. ${ }^{21}$ However, this does not necessarily mean that ethnic minorities have better access to the housing market, namely in a context marked by an increase in the prices of new housing. A decrease in segregation may be achieved through the arrival of wealthier Dutch newcomers in some rehabilitated housing pockets 
in the old deprived neighbourhoods. However, as noted by Kempen and Weesep (1998: 1830-31), the reduced opportunities for lowincome households, namely those belonging to the ethnic minority groups, may lead to the development of new concentration areas, reversing the trends of decreasing segregation indices.

With respect to the Lisbon Metropolitan Area, an incipient relationship between urban policies and ethnic minorities only became visible after the launch of the Special Relocation Programme (PER) in 1993. Although the promotion of public housing in Portugal started in the 1910s, the programmes that developed subsequently - including the large housing estates built in the 1970s and 1980shave kept a rule excluding foreigners. The implementation of PER changed this situation and opened the door to the relocation of foreigners into public housing.

Unlike Rotterdam, Lisbon has a peripheral distribution of ethnic minorities in public housing, shanties and clandestine dwellings. So, besides urban rehabilitation, slum clearance and re-housing are very important policy goals in the agenda of Portuguese national and local authorities. Until the early 1990s, the development of slum clearance programmes was very slow, leading to a progressive degradation of living conditions in the shanty quarters settled in previous decades. Around 1991, social leaders from NGOs, the Catholic Church and even some political parties joined the population of some slums in demonstrations demanding better housing conditions and faster re-housing programmes. The combination of these demands with the development of the National Programme Against Poverty led the Cabinet to launch the PER, a programme aiming to eradicate slums in the Metropolitan Areas of Lisbon and Oporto. Like the Dutch BCP, the implementation of this programme results from a joint effort of national government and the municipal authorities of the Metropolitan Areas.

Despite its positive character, it is excessively focused on the physical dimension, largely neglecting the social and economic components of the process. Also, the implementation of strategies leading to a higher involvement of local populations in the reloca- tion processes have been downplayed by most municipalities. This means that public authority paternalism and dependency (from the point of view of residents) still prevail. Finally we are on the verge of a new stage in the development of the PER policy, characterised by smaller re-housing schemes, increased social participation and eventually programme evaluation (Crozat, 1997). In 1996, the recently elected socialist Cabinet introduced more flexibility to the programme through the introduction of 'PER-families', providing subsidies for families who want to buy a house in the free market.

Created and developed when the framework supporting the pre-policy of immigration appeared, the PER represented an innovative contribution to the relationship between public housing policy and the social insertion of immigrant populations. Firstly, it enabled the systematic collection of demographic and housing data that made the social and spatial situation of ethnic minorities visible and known to the general public. Secondly, the relocation process has required increasing cooperation between local authorities and their populations, namely in organisations (Marques et al., 1999) to stimulate the activities of the latter (at least during the relocation process). Finally, some municipal authorities went further in the flexibility of the programme and started to support individual relocation processes in the country of origin (normally for retired persons).

The implementation of the EU URBAN initiative in Portugal since 1994, as well as its national complement (the Urban Rehabilitation Programme), has also contributed to the development of local policies that take into consideration the specific features of foreign populations. Several peripheral quarters benefiting from these two programmes (Outurela/ Portela in Oeiras, Venda Nova/Damaia de Baixo in Amadora, Vale da Amoreira in Moita) developed actions aimed at specific features of foreign groups (African Cultural Week of Vale da Amoreira, parents' education in Outurela/ Portela, an inter-cultural school in Venda Nova/Damaia de Baixo).

All these initiatives contribute to an improvement in the living conditions of the groups of foreign origin in the Metropolitan 
Region of Lisbon, mainly at the physical level (housing and facilities) but potentially at the socio-economic one. However, the dominant strategies within PER and even within URBAN do not seem to counteract the locational patterns of the non-EU population. In fact, there are expectations that segregation levels increased in the 1990s, a situation that the census of 2001 may reveal. If the policy trends that started to be adopted in the late 1990s prevail, not only might a reduction in segregation levels be expected in future, but there may also be a gradual improvement of social relations in derelict and stigmatised quarters of clandestine and public housing.

\section{CONCLUSIONS - A VIEW FROM THE SOUTH-WEST}

The issue of ethnic segregation in European cities has recently been discussed by authors like Peach (1996), Kempen and Weesep (1998) and Musterd et al. (1998). Although in some cases a balance between advantages (relative social stability, potential cohesion at the neighbourhood level) and disadvantages (social inequity, lack of understanding between groups settled in different areas, reduced participation opportunities for those clustering in poor areas) of spatial separation along socioethnic lines is developed, most of literature focuses on the negative elements. The debate around spatial segregation is still under the influence of the American research tradition, whereby the black ghetto is the extreme reference point. In this sense, contemporary Western European policy-makers have tried to implement measures to prevent (or at least to counteract) the development of segregated areas, especially if segregation meant the concentration of under-privileged ethnic minorities.

In our opinion, socio-ethnic segregation is not necessarily negative. In the Lisbon Metropolitan Area, the English register the highest segregation levels and that is not considered a problem; likewise with Japanese clusters in London or in Auderghem (Brussels suburbs). 'Problems' are not in population clusters but in the spatial coexistence of poor people and poor environments, unemployment, drug trafficking, high crime rates, lack of economic dy- namics and neighbourhood cohesion, social tension and negative local images. The issue is liveability, not segregation.

However, perhaps because social and ethnic segregation levels are lower in Southern European cities, they do not consider the promotion of social mix as a major goal of local policies, especially if this means the 'import' of external residents who tend to establish only low levels of interaction with the current residents, due to their social distance.

In this paper we tried to test a hypothesis related to the specific features of the spatial organisation of immigrants and ethnic minorities in the cities of Southern Europe. This hypothesis assumes that, besides their specific housing problems, ethnic minorities largely rely on the informal housing market, present lower levels of spatial segregation, and are less concentrated in the inner city. Most of the evidence coming from the data analysis and the literature seems to confirm the hypothesis, although in several metropolises, geographical over-representation may be found both in peripheries and in decaying inner city areas. However, the limited amount of research on the spatial situation of foreigners in Southern European cities, as well as the problems of comparability of intra-urban statistical information for the different EU metropolisses, justify further cross-comparative analysis on this subject.

Finally, taking into consideration the hypothesis presented and the elements of the Dutch urban policy, what lessons can we learn from the Lisbon situation?

Firstly, there are two common trends in urban rehabilitation policies (decentralisation to local authorities and integrated approaches) which represent a very positive path in the direction of empowerment and the potential involvement of local populations. However, a new intervention culture must be developed in Portuguese municipalities, breaking with the traditional functionalist, paternalist and bureaucratic attitudes developed by certain local politicians and municipal technicians. Empowerment of the residents, and new ways of spreading information by reinforcing direct field contacts instead of bureaucratic procedures, are critical issues, especially in relocation initiatives such as PER. 
The strong suburbanisation of minorities in the case of Lisbon, comparable to some French metropolises, especially Paris, requires a spatially integrated approach because links (physical, symbolic, informational) between targeted residential neighbourhoods and working and leisure areas must be taken into consideration. Within this dimension, the situation of the Portuguese capital has some potential, at least theoretically. An administrative metropolitan body involving the 19 municipalities has been established since 1991; however, its effective action in the development of innovative policies at the metropolitan scale is clearly below expectations.

The Dutch examples of appointing a minister for the cities and also of an integrated policy for the urban centres can be considered good guidelines for the development of a coordinated approach involving central and local authorities. However, in the Portuguese case this coordinated approach could be based on the one hand in increasing metropolitan cooperation at the municipal level and, on the other hand, in strategic trans-sectoral metropolitan programmes, bringing together the Cabinet and the local authorities.

In the case of Lisbon, the relevance of private ownership of urban land, as well as the high level of informalisation of certain segments of the housing market, makes planning strategies and public interventions more complex. However, the old culture of buying houses instead of renting, and the informal practices developed both in illegal construction and in realestate transactions, may help the development of some innovative experiences like the promotion of self-construction or 'evolutive' housing.

\section{NOTES}

(1) The author wishes to thank Gabriella Lazaridis, Allan Williams, Maria José Caldeira and anonymous referees for their useful comments on earlier versions of this text. However, the opinions expressed in the paper remain the full responsibility of the author.

(2) Technically, the segregation levels observed for a certain group increase with the degree of spatial concentration of the group. In other words, if the spatial distribution of a certain group presents a pattern far from a uniform spatial distribution, we are in the presence of segregation. For more details about these questions, see Kempen and Özückren (1998: 1632-3).

(3) Free translation of the Portuguese version.

(4) The definitions of ethnic quarter (an area where a group constitutes the majority of the population without being absolutely dominant and exclusively concentrated in that area) and concentration area (over-representation of a certain ethnic, racial or religious group that is still a minority in the area) presented by Van Amersfoort (1990) are close to the Peach notion of reputational ghetto.

(5) Blom (1999), for the case of Oslo; Peach (1996) for the English cities; and Musterd et al. (1998) for Amsterdam, Brussels and other Northern European metropolises.

(6) These indicators are: (i) percentage of nationals; (ii) percentage of non-EU foreigners; (iii) relationship between the percentages of non-EU foreigners and EU-foreigners; (iv) variation rate of the nationals; (v) approach to the relationship between the percentages of nationals in the centre and in the periphery; (vi) approach to the relationship between the percentages of non-EU foreigners in the centre and in the periphery. For the metropolis chosen for analysis, the database included both information for the administrative unit corresponding to the city and for the conurbation (this kind of information was not available for German cities in the Urban Audit Database). The definitions of the different conurbations were established by the Urban Audit experts on the basis of administrative or urban continuous areas with demographic densities over 500 hab. $/ \mathrm{km}^{2}$.

(7) Technically, this typology is based on a bottom-up methodology of cluster analysis, using Ward's method and Euclidean distance.

(8) The small cities of Luxembourg are not included in the database, and neither are the megalopolis of Paris and London [www.inforegio.cec.eu.int/urban/audit].

(9) This period is taken as a global reference, because there are differences in the moments of the major flows registered in each one of the countries.

(10) Some summary information about this process for the Spanish case can be found in Lago Avila (1999: 216-17). According to the information presented by this author, there were 98,793 shacks registered in 1973 in Spain, a number that had been reduced to 29,497 in 1990 . 
(11) Approximately $40 \%$ in the Netherlands, over $20 \%$ in Denmark, Sweden and the UK (Heijden, 1999; Kristensen, 1999), but only around $5 \%$ in Italy and Portugal (Pallida, 1998; Silva, 1999).

(12) Because two cities of the UK were already selected and we were not able to obtain data for Copenhagen or Lille, it was decided to include Brussels in the analysis in order to have four cities of Northern Europe. Although Brussels was not treated in the overview section, evidence from the literature (e.g. Kesteloot and Cortie, 1998) point to patterns close to the situation identified in Group 1 of the tree-diagram.

(13) A person is classified in a certain ethnic group established on a national basis if himself or one of his parents was born in the country of origin of that group of population.

(14) According to SOPEMI data, the average naturalisation rate for the Netherlands, between 1994 and 1998, was close to 9\%, whereas in almost all the other EU countries it was below 4\% (OCDE SOPEMI, 2000). In Southern European countries like Italy, Spain or Portugal, these values fall to less then $2 \%$.

(15) The segregation index takes as reference the one developed by the Duncans in 1955 and corresponds to the one used by Petsimeris (1995). It was calculated as follows:

$$
\mathrm{SI}=1 / 2 \sum_{\mathrm{i}=1}^{\mathrm{n}}\left|\mathrm{x}_{\mathrm{i}}-\mathrm{y}_{\mathrm{i}}\right|^{*} 100
$$

where $\mathrm{x}$ corresponds to the relationship between an immigrant group in the i region and the global population of that group in the whole area of study;

$y$ corresponds to the relationship between the population of all the other groups in the region $i$ and the population of all the other groups in the whole area of study; and

$\mathrm{n}$ is the number of spatial units considered. This segregation index ranges between 0 (perfect distribution-social and/or ethnic mix) and 100 (extreme segregation).

(16) On this question, see Palidda (1998) for the case of Italy, and Malheiros (2000) for Portugal.

(17) In discussions with policy-makers and researchers of different cities (e.g. Berlin, Luxembourg-ville, Barcelona, Loures in the outskirts of Lisbon), this image of Rotterdam as a reference in the fields of urban and social renewal was mentioned several times. This is also recognised as a comparative advantage of this city in an analysis developed by Muskens (1996).
(18) In the case of the Netherlands, this concept is used to classify population groups (Surinamese, Antillians, Moroccans, Turks, Cape Verdeans and North Mediterraneans) who are the targets of specific assistance policies. Belonging to an ethnic minority results from the fulfilment of one of three criteria: being born in the country of that ethnic origin, or being born from a mother or a father who are natives of that country.

(19) Good critical discussions of the BCP can be found in Priemus et al. (1997) and also in Kempen (2000).

(20) Later on, 21 middle-sized cities were also included in the policy.

(21) For instance, the segregation indices of Turks in Rotterdam have decreased from 53.5 in 1988 to 49.6 in 1998. In the same period, the segregation indices of Moroccans declined from 49.8 to 44.0 and those registered by Cape Verdeans from 48.5 to 44.1 .

\section{REFERENCES}

Almeida AN. 1993. A Fábrica e a Família: famílias operárias no Barreiro. Camara Municipal do Barreiro, Colecção Estudos e Documentos sobre a História Local: Barreiro.

Van Amersfoort H. 1990. La répartition spaciale des minorités ethniques dans un état providence: les leçons des Pays Bas 1970-1990. Espaces, Populations, Sociétés 2.

Anderiesse RM, Bol P, Oudijk CH, Boms CP. 1999. Migration and major cities policy in Rotterdam. In From Metropolis to Cosmopolis, Hjarno J (ed.). DCMES/South Jutland University Press; Esbjerg; 165-218.

Auge M. 1994. Não-Lugares. Introdução a uma antropologia da sobremodernidade. Bertrand Editora: Lisbon.

Baganha MI. 1996. Immigrant Insertion in the Informal Economy-The Portuguese Case. Coimbra, CESUniversidade de Coimbra ( $1^{\text {st }}$ Report).

Baganha MI, Ferrão J, and Malheiros JM. 1999. Immigrants and the Labour Market: the Portuguese Case. Proceedings of the Metropolis International Workshop, Lisbon, 28-29 Sept. 1998. Luso-American Development Foundation: Lisbon; 89-120.

Baldwin-Edwards M. 1998. Where free markets reign: aliens in the Twilight Zone. South European Society and Politics 3(3): 1-15.

Ball M, Bentivegma V, Edwards M, Folim M. 1985. Land Rent, Housing and Urban Planning. A European Perspective. London, Croom Helm.

Barata Salgueiro T et al. 1997. Internacionalização, Reestruturação Económica e Produção de Novas 
Marginalidades na Região de Lisboa. Project Report, Lisbon, DGOTDU (unpublished).

Blom S. 1999. Residential concentration among immigrants in Oslo. In Metropolis to Cosmopolis, Hjarno J (ed.). South Jutland University Press: Esbjerg; 310-328.

Buckley Iglesias M. 1998. Inmigración y comercio en Madrid. Nuevos negocios para nuevas gentes. Anales de Geografia de la Universidad Complutense 18: 283-297.

Crozat D. 1997. Vers la fin des bidonvilles à Lisbonne. Finisterra 32(64): 71-96.

Cullingworth JB. 1993. The Political Culture of Planning. Routledge: New York.

De Jong W, Verkuyten M. 1996. Urban renewal, housing policy and ethnic relations in Rotterdam. New Community 22(4): 671-687.

Engels F. 1844/1975. A situação da classe trabalhadora em Inglaterra. Afrontamento: Porto.

Esping-Andersen G. 1990. Three worlds of welfare capitalism Polity Press: Cambridge.

Ferreira MC. 1993. Emprego e Reprodução Social num Contexto de Mudança: a indústria do vidro na Marinha Grande. MA thesis, Instituto Superior de Ciências do Trabalho e da Empresa, Lisbon.

Fonseca ML. 1999. Immigration, Socio-spatial Marginalisation and Urban Planning in Lisbon: Challenges and Strategies. Proceedings of the Metropolis International Workshop, Lisbon, 28-29 Sept. 1998. Lisbon, Luso-American Development Foundation: Lisbon; 187-214.

Frangouli-Papantoniou M. 1999. Modes of Insertion of Illegal Migrants in the Labour Market: The Case of Greece. Proceedings of the Metropolis International Workshop, Lisbon, 28-29 Sept. 1998. Luso-American Development Foundation: Lisbon; $121-140$.

Giffinger R. 1998. Segregation in Vienna: Impacts of Market Barriers and Rent Regulations. Urban Studies 35(10), October: 1791-1812.

Guglielmo R. 1996. Les Grandes Métropoles du Monde et leur crise. Armand Colin: Paris.

Harvey D. 1990. The Condition of Postmodernity. Blackwell: Oxford.

Heijden $\mathrm{H}$ van. 1999. The future of the social rented sector in Western Europe. In ENHR/cecodhas conference Social Housing Policy, 18-19 Feb. 1999, Nunspeet.

Kempen R Van. 2000. Big Cities Policy in The Netherlands. Tijdschrift voor Economische en Sociale Geografie 91(2): 197-203.

Kempen R Van, Özüekren AS. 1998. Ethnic Segregation in Cities: New forms and Explanations in a Dynamic World. Urban Studies 35(10): 1631-1656.

Kempen R Van, Weesep J van. 1998. Ethnic Residential Patterns in Dutch Cities: Back- grounds, Shifts and Consequences. Urban Studies 35(10): 1813-1834.

Kesteloot C, Cortie C. 1998. Housing Turks and Moroccans in Brussels and in Amsterdam: The Difference between Private and Public Markets. Urban Studies 35(10): 1835-1854.

King R. 2000. Southern Europe in the Changing Global map of Migration. In Eldorado or Fortress: Migration in Southern Europe, King R, Lazaridis G, Tsardanidis C (eds). Macmillan Press: London, 127.

King R, Fielding A, Black R. 1997. The International Migration Turnaround in Southern Europe. In Southern Europe and the New Immigrations, King R, Black R (eds). Brighton, Sussex Academic Press: $1-26$.

King R, Iosifides T. 1998. Socio-Spatial Dynamics and Exclusion of Three Immigrant Groups in the Athens Conurbation. South European Society and Politics 3(3): 205-229.

Kloosterman R. 1998. Migration in the Netherlands and the emerging post-industrial divide in urban areas. In EC Proceedings: Immigrants, Integration and Cities - Exploring the Links. OECD: Paris; 7390.

Kristensen H. 1999. Social housing policy and the Welfare State - a Danish perspective. In ENHR/ cccodhas-conference, Social Housing Policy, 18-19 Feb. 1999, Nunspeet.

Lago Avila MJ. 1999. Ethnic Minorities and Housing Problems. Proceedings of the Metropolis International Workshop, Lisbon, 28-29 Sept. 1998. Lisbon, LusoAmerican Development Foundation: 215-230.

Lazaridis G, Psimmenos I. 2000. Migrant Flows from Albania to Greece: Economic, Social and Spatial Exclusion. In Eldorado or Fortress: Migration in Southern Europe, King R, Lazaridis G, Tsardanidis C (eds). Macmillan Press: London, 170-185.

Leontidou L. 1993. Post-modernism and the city: Mediterranean versions. Urban Studies 30(6): 949965.

Malheiros JM. 2000. Urban Restructuring, Immigration and the Generation of Marginalised Spaces in the Lisbon Region. In Eldorado or Fortress: Migration in Southern Europe, King R, Lazaridis G, Tsardanidis C (eds). Macmillan Press: London, 207-232.

Marques M, Santos R, Ralha T. 1999. Divided cities: best practices for the social inclusion of the ethnic minorities in local communites. In 4th International Metropolis Conference, Washington DC (mimeo).

Massey DS, Denton NA. 1993. The American Apartheid-Segregation and the Making of Underclass. Harvard University Press: Cambridge, MA.

Mingione E. 1995. Labour market segmentation and 
informal work in Southern Europe. European Urban and Regional Studies 2(2): 121-143.

Muskens G. 1996. Multiculturalism and Political Integration in the Netherlands: Rotterdam, Enschede. Innovation 9(1): 33-49.

Musterd S, Deurloo R. 1997. Ethnic Segregation and the Role of Public Housing in Amsterdam. Tidjschrift voor Economische en Sociale Geografie 88(2): 158-168.

Musterd S, Ostendorf W. 1996. Amsterdam: Urban change and the welfare state. In Social Polarisation in Post-Industrial Metropoli, O'Loughlin J, Friedrichs J (eds). Walter de Gruyter: New York; 7194.

Musterd S, Ostendorf W, Breebaart M. 1998. MultiEthnic Metropolis: Patterns and Policies. Kluwer Academic Publishers: Dordrecht.

Niessen J, Kruyt A. 1997. Integration. In Immigrant Policy for a Multicultural Society, Vermeulen $\mathrm{H}$ (ed.). MPG-IMES: Brussels; 15-56.

OCDE/SOPEMI 2000. Tendances des migrations internationales - Sopemi 2000. OCDE: Paris.

Oude Engberink G. 1999. Contribution by the City of Rotterdam. European Conference on 'What Participation by Foreign Residents in Public Life at Local Level' Strasbourg, 5-6 Nov. 1999. (unpublished).

Pallida S. 1998. The integration of immigrants in changing urban environments: the example of Italy. In EC Proceedings: Immigrants, Integration and Cities - Exploring the Links. OCDE: Paris; 117-136.

Peach C. 1996. Does Britain have ghettos? Transactions of the Institute of British Geographers. New Series 21(1): 216-235.

Petsimeris P. 1995. Une méthode pour l'analyse de la division ethnique et sociale de l'espace intramétropolitain du Grand Londres. L Espace Geographique 1995 2: 139-154.
Priemus H, Boelhouwer P, Kruythoff H. 1997. Dutch Urban Policy: a promising perspective for the Big Cities. International Journal of Urban and Regional Research: 677-690.

Ribas Mateos N. 1999. Notes on a Southern European Model - Immigration, the Welfare State and the Family. Universidad Autónoma de Barcelona.

dS + V. 1999. The Rotterdam Wijkaanpak. Department of Urban Planning and Housing, Municipality of Rotterdam (Bureau Wijkaanpak).

SCP 1996. Social and Cultural Report, 1996. Social and Cultural Planning Office: Rijswijk.

Smakman N, and Musterd S. 1999. Homogeniteit in plaats van heterogeniteit!. Tijdschrift voor de Volkshuisvesting, 1999/3, pp. 27-34.

Silva C. 1999. Local government, ethnicity and the social exclusion in Portugal. In Urban renewal, ethnicity and the social exclusion in Europe, Khakee A, Somma P, Thomas H (eds). Ashgate: Aldershot; $126-146$.

Tosi A, Lombardi M. 1999. Spatial Concentration and Mobility in Milan. Proceedings of the Metropolis International Workshop, Lisbon, 28-29 Sept. 1998. Luso-American Development Foundation: Lisbon; 15-38.

Werth M, Körner H. 1991. L'Immigration de Ressortissants de Pays Tiers dans les Etats Meridionaux de la $C E$. CCE-Direction Générale de L'Emploi, des Relations Industrielles et des Affaires Sociales, Supplément 1/91.

Wilson WJ. 1987. The Truly Disadvantaged. The Inner City, The Underclass, and Public Policy. University of Chicago Press: Chicago.

Wilson WJ. 1997. When Work Disappears: The World of Urban Poor. Vintage Books: New York.

Wong DWS. 1997. Spatial dependency of segregation indices. Canadian Geographer, 41(2): 128-136. 